\title{
Rapid Repair of Severely Damaged RC Columns with Different Damage Conditions: An Experimental Study
}

\author{
Ruili He ${ }^{1)}$, Lesley H. Sneed ${ }^{1), *}$, and Abdeldjelil Belarbi' ${ }^{2)}$
}

(Received December 31, 2012, Accepted February 13, 2013)

\begin{abstract}
Rapid and effective repair methods are desired to enable quick reopening of damaged bridges after an earthquake occurs, especially for those bridges that are critical for emergency response and other essential functions. This paper presents results of tests conducted as a proof-of-concept in the effectiveness of a proposed method using externally bonded carbon fiber reinforced polymer (CFRP) composites to rapidly repair severely damaged RC columns with different damage conditions. The experimental work included five large-scale severely damaged square RC columns with the same geometry and material properties but with different damage conditions due to different loading combinations of bending, shear, and torsion in the previous tests. Over a three-day period, each column was repaired and retested under the same loading combination as the corresponding original column. Quickset repair mortar was used to replace the removed loose concrete. Without any treatment to damaged reinforcing bars, longitudinal and transverse CFRP sheets were externally bonded to the prepared surface to restore the column strength. Measured data were analyzed to investigate the performance of the repaired columns compared to the corresponding original column responses. It was concluded that the technique can be successful for severely damaged columns with damage to the concrete and transverse reinforcement. For severely damaged columns with damaged longitudinal reinforcement, the technique was found to be successful if the damaged longitudinal reinforcement is able to provide tensile resistance, or if the damage is located at a section where longitudinal CFRP strength can be developed.
\end{abstract}

Keywords: CFRP composites, cyclic loading, rapid repair, RC columns, severely damaged.

\section{Introduction}

Damage to bridge structures during an earthquake can have devastating social and economic consequences, particularly for bridges located along key routes that are critical for emergency response and other essential functions. Such bridges are defined as "important" by ATC-18 (1997), which stipulates that full access to "important" bridges should be possible within three days after an earthquake. In order to restore access to essential traffic in affected areas, rapid and effective repair methods are desired for varying levels of damage to minimize the impact on the community.

Decades of study have demonstrated the effectiveness of externally bonded fiber reinforced polymer (FRP) in strengthening and repairing reinforced concrete (RC) columns. Most studies have focused on flexural or shear strengthening or repair application of various types of members or providing

\footnotetext{
${ }^{1)}$ Department of Civil, Architectural \& Environmental

Engineering, Missouri University of Science and Technology, Rolla, MO 65409, USA.

*Corresponding Author; E-mail: sneedlh@mst.edu

${ }^{2)}$ Department of Civil \& Environmental Engineering, University of Houston, Houston, TX 77204, USA.

Copyright $($ The Author(s) 2013. This article is published with open access at Springerlink.com
}

confinement in case of columns. Among the studies on repair, most have focused on columns with slight or moderate damage in which concrete, steel, or FRP jacketing was used to restore the strength and displacement capacity (Elkin et al. 1999; Stoppenhagen et al. 1995; Chai et al. 1991; Saadatmanesh et al. 1997; Cheng et al. 2003). Few studies, however, have focused on repairing severely damaged ductile RC bridge columns, especially those with buckled or fractured longitudinal reinforcing bars (Elkin et al. 1999; Cheng et al. 2003). Although these techniques have been shown to be effective in restoring the strength and displacement capacity, rapid repair was not emphasized, and timely reopening of the bridge was not a consideration. To address this issue, Vosooghi and Saiidi (Vosooghi and Saiidi 2012) recently developed guidelines for rapid repair of damaged bridge columns with carbon FRP (CFRP). Their studies focused on circular RC bridge columns under flexural and shear loading conditions without ruptured longitudinal reinforcing bars.

Bridge columns may experience complex axial, shear, bending, and torsional loading during an earthquake. As shown by Prakash et al. (2012), interaction between loading actions influences the location and type of damage. Therefore, it is of interest to develop a repair technique for damaged columns with different damage conditions resulting from combined loading effects.

The present study was conducted as a proof-of-concept with the objective of determining the feasibility and 
effectiveness of a proposed technique to rapidly repair severely damaged RC bridge columns with different damage conditions using externally-bonded CFRP for emergency service use after an earthquake. The term "rapid" in the context of this study refers to a three-day time period as defined by ATC-18 (1997) and other researchers (Vosooghi et al. 2008). This research will fill in critical gaps in the literature with respect to the severe damage level and inclusion of torsional loading effects and will help guide future research efforts in this area. This experimental study included five half-scale square bridge columns that were tested to complete failure under different combined loading effects of axial, shear, bending, and torsion in a previous study (Prakash et al. 2012). After the previous tests, the columns were severely damaged with different damage conditions. Each column was repaired within a three-day period and retested on the fourth day under the same combined loading as the corresponding original column. The performance of the repaired columns was evaluated by comparing the response with that of the corresponding original columns. The large scale nature of the test specimens in this study allowed for evaluation of the constructability of the developed repair technique in practice.

\section{Original Columns}

Five square RC columns were tested in a previous study, each with the same nominal geometry and material properties. The columns were $1 / 2$ scale bridge columns designed based on CALTRANS (2004) and ACI 318 (2008) seismic provisions. The column specimen was simulated as a cantilever, and the aspect ratio (H/B) was 6 , where $\mathrm{H}$ and $\mathrm{B}$ are the height of the column and the cross-section dimension, respectively. Figure 1 shows the column geometry and reinforcement details. The column was 22 in. $(560 \mathrm{~mm})$ square reinforced with four No. 9 (29 mm dia.) deformed bars in the corners and eight No. 8 (25 mm dia.) intermediate bars, with a longitudinal reinforcement ratio of $2.13 \%$. Tie reinforcement consisted of square and octagonal No. 3 (10 $\mathrm{mm} \mathrm{dia.)} \mathrm{deformed} \mathrm{bars} \mathrm{spaced} \mathrm{at} 3.25 \mathrm{in}$. (82 mm), with a transverse reinforcement ratio of $1.32 \%$. The measured yield strength of the longitudinal bars was $76 \mathrm{ksi}$ (524 MPa) for No. $8(25 \mathrm{~mm} \mathrm{dia.)} \mathrm{bars} \mathrm{and} 67 \mathrm{ksi}$ (462 MPa) for No. 9 (29 mm dia.) bars. For the ties, the measured yield strength was $74 \mathrm{ksi}(510 \mathrm{MPa})$. Yield strength of the reinforcing bars was determined in accordance with ASTM A 370 (2012). The target 28-day cylinder compressive strength of the concrete was 5,000 psi (34 MPa). Additional information including measured concrete properties is provided in Prakash et al. (2012).

The previous research studied the seismic performance of square RC bridge columns under combined loading effects including torsion. The study was focused on the interaction between bending and torsion, and the primary variable was the torque-to-moment ratio (T/M). All five columns were tested to failure under cyclic lateral loading and a constant axial load of approximately 150 kips $(667 \mathrm{kN})$ to simulate the dead load from the superstructure. Column 1 was subjected to cyclic uniaxial cantilever bending and shear $(\mathrm{T} / \mathrm{M}=0)$ in addition to the constant axial load. Columns 2, 3 , and 4 were subjected to the constant axial load and a combined cyclic loading effect of uniaxial cantilever bending, shear, and torsion, with torque-to-moment ratios (T/M) of $0.2,0.4$, and 0.6 , respectively. Column 5 was tested under pure torsion $(\mathrm{T} / \mathrm{M}=\infty)$ in addition to the constant axial load.

\section{Column Damage Conditions}

After the original tests, the columns were severely damaged with different damage conditions due to the different combined cyclic loading effects (T/M). The overall damage conditions were classified based on both visual observations and measured response data. According to previous work (Lehman et al. 2001), any visible evidence of core concrete crushing, longitudinal bar buckling, or longitudinal/transverse reinforcement fracture is classified as severe damage. Damage is classified as significant according to ATC 32 criteria if a permanent offset is apparent, if the reinforcement has yielded, or if major concrete spalling has occurred (Rojahn et al. 1997). The terms "significant" and "severe" are used interchangeably in this paper when referring to the column damage.

The damaged columns after the original tests are shown in Fig. 2, which illustrates the difference in the visible damage extent and the plastic hinge location. Generally, the damage region extended farther along the column height and the plastic hinge location shifted away from the base with increasing torque-to-moment ratio. For instance Column 1, which was tested under cyclic shear and bending, sustained cover concrete spalling $25 \mathrm{in}$. $(635 \mathrm{~mm})$ above the column base, and the plastic hinge was located approximately $10 \mathrm{in}$. (260 $\mathrm{mm}$ ) above the base. Column 5, which was subject to cyclic torque moment, exhibited concrete damage that extended almost the entire column length, and the core concrete crushed through the cross section 64 in. $(1,620 \mathrm{~mm})$ above the column base. The damage to Columns 1, 2, and 3 was concentrated near the base of the column at the location of maximum moment due to flexuredominant behavior in columns with low $\mathrm{T} / \mathrm{M}$ ratios $(\mathrm{T} / \mathrm{M}$ $<0.5$ ). Columns 4 and 5 were torsion-dominant with high $\mathrm{T} / \mathrm{M}$ ratios $(\mathrm{T} / \mathrm{M}>0.5)$, which resulted in higher plastic hinge location and larger damage extent as illustrated in Fig. 2.

Measured data acquired during testing were used to monitor changes in load-displacement response and determine locations at which the reinforcement yielded. At completion of testing, the load-displacement responses showed that the stiffness of each column decreased significantly, and the residual strength was less than $50 \%$ of the peak load. Some of the columns were completely damaged without any resistance to the applied loading (Prakash et al. 2012). 


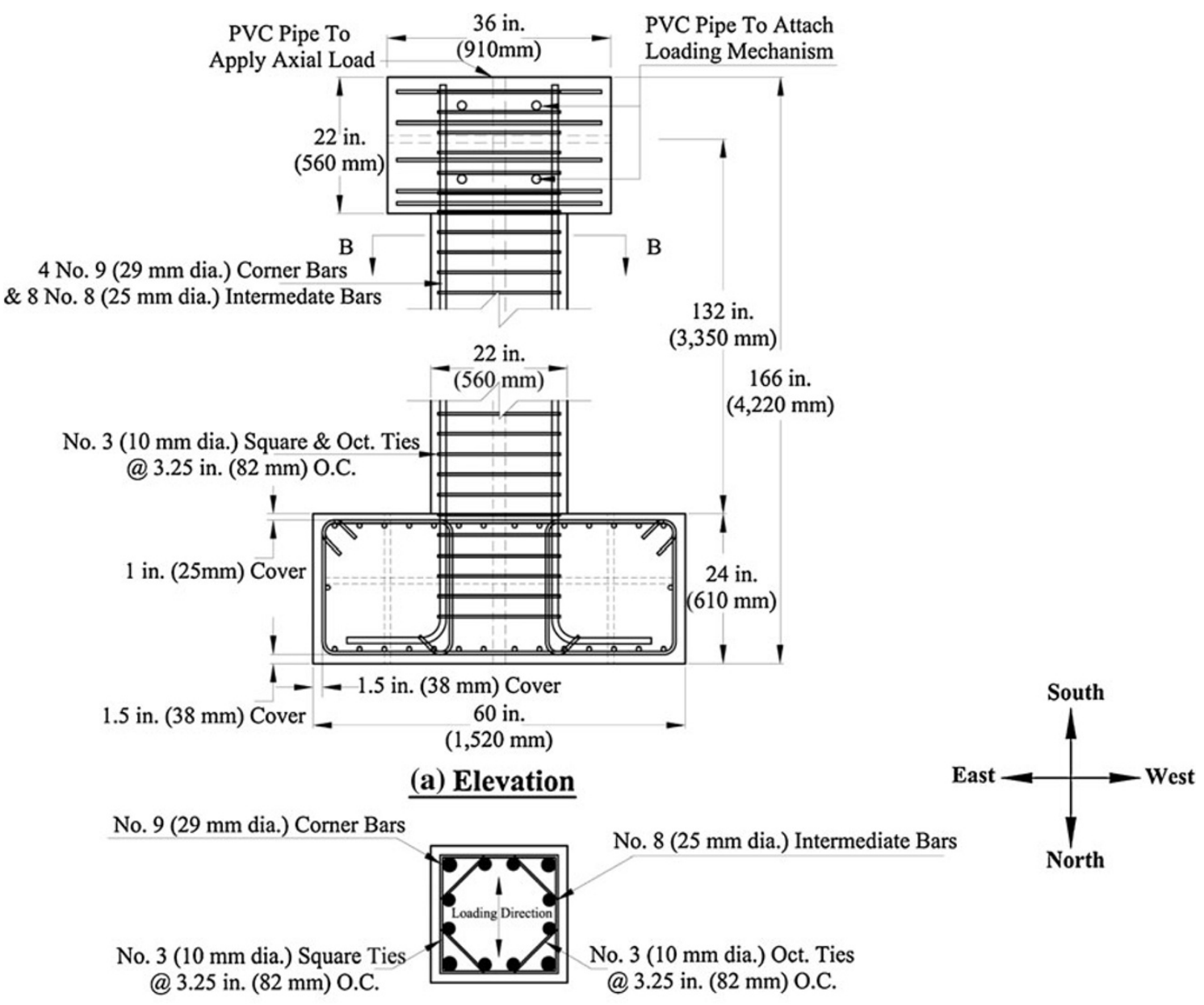

(b) Cross Section B-B

Fig. 1 Geometry and reinforcement details of original columns.

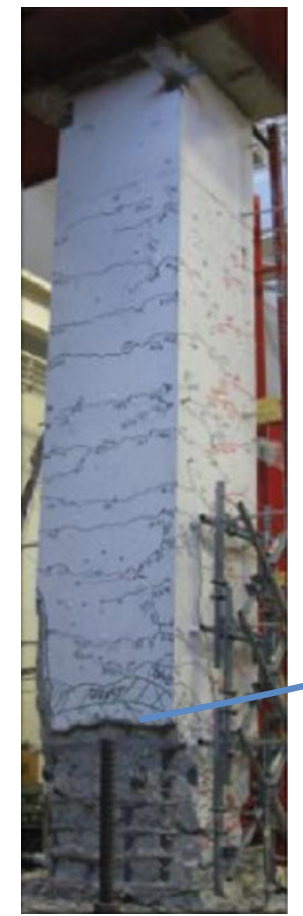

Column $1(\mathrm{~T} / \mathrm{M}=0)$

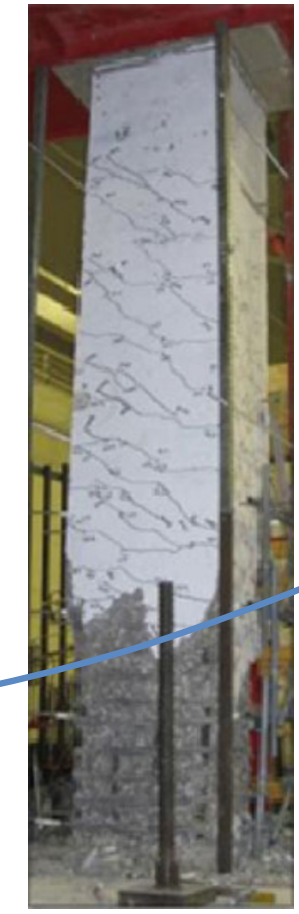

Column $2(\mathrm{~T} / \mathrm{M}=0.2)$

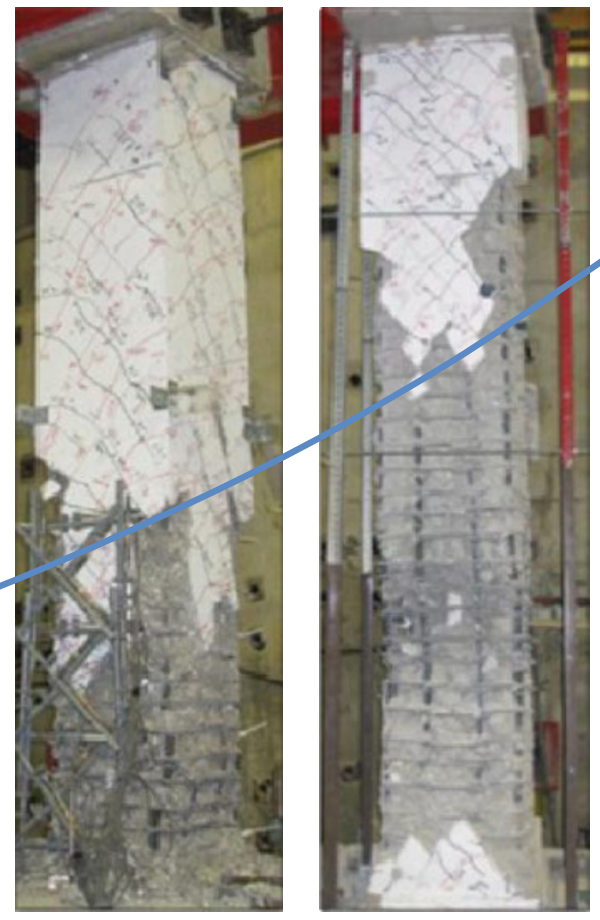

Column 4 (T/M=0.6)

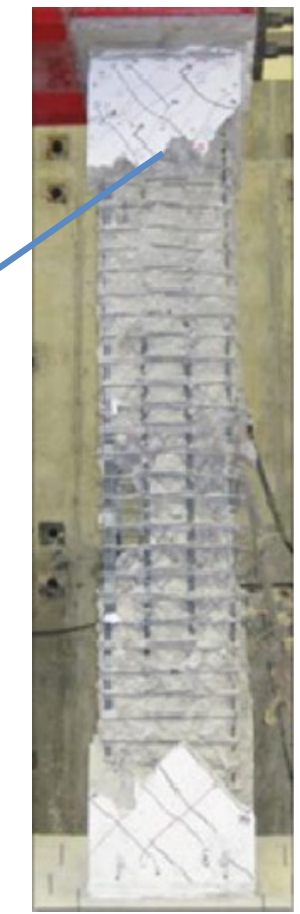

Column $5(\mathrm{~T} / \mathrm{M}=\infty)$

Fig. 2 Damage conditions of the original columns after previous tests. 
Table 1 Summary of damage to original columns.

\begin{tabular}{|c|c|c|c|c|c|c|c|}
\hline \multirow[t]{3}{*}{ Column } & \multirow[t]{3}{*}{$\mathrm{T} / \mathrm{M}$} & \multirow{2}{*}{\multicolumn{2}{|c|}{ Concrete damage }} & \multicolumn{4}{|c|}{ Reinforcing bar damage } \\
\hline & & & & \multicolumn{3}{|c|}{ Longitudinal } & \multirow[t]{2}{*}{ Ties $^{\mathrm{a}}$} \\
\hline & & Cover spall & Core crush & Yield & Buckle & Fracture & \\
\hline Column 1 & 0 & $\begin{array}{c}25 \text { in. }(635 \mathrm{~mm}) \\
\text { above column } \\
\text { base }\end{array}$ & $\begin{array}{c}10 \text { in. }(260 \mathrm{~mm}) \\
\text { above column } \\
\text { base }\end{array}$ & All bars & $\begin{array}{c}\text { All bars, } 10 \mathrm{in} . \\
(260 \mathrm{~mm}) \\
\text { above column } \\
\text { base }\end{array}$ & $\begin{array}{l}2 \text { bars; } 10 \text { in. } \\
\text { (260 mm) } \\
\text { above column } \\
\text { base (see } \\
\text { Fig. } 1)\end{array}$ & 4 ties \\
\hline Column 2 & 0.2 & $\begin{array}{c}37 \text { in. }(950 \mathrm{~mm}) \\
\text { above column } \\
\text { base }\end{array}$ & $\begin{array}{c}20 \text { in. }(500 \mathrm{~mm}) \\
\text { above column } \\
\text { base }\end{array}$ & All bars & $\begin{array}{c}10 \text { bars, } 20 \text { in. } \\
(500 \mathrm{~mm}) \\
\text { above column } \\
\text { base }\end{array}$ & None & 3 ties \\
\hline Column 3 & 0.4 & $\begin{array}{c}58 \text { in. } \\
(1,470 \mathrm{~mm}) \\
\text { above column } \\
\text { base }\end{array}$ & $\begin{array}{c}30 \text { in. }(760 \mathrm{~mm}) \\
\text { above column } \\
\text { base }\end{array}$ & All bars & $\begin{array}{l}10 \text { bars, } 30 \mathrm{in} . \\
(760 \mathrm{~mm}) \\
\text { above column } \\
\text { base }\end{array}$ & None & 1 tie \\
\hline Column 4 & 0.6 & $\begin{array}{c}94 \text { in. } \\
(2,380 \mathrm{~mm}) \\
\text { above column } \\
\text { base }\end{array}$ & $\begin{array}{c}40 \mathrm{in} . \\
(1,020 \mathrm{~mm}) \\
\text { above column } \\
\text { base }\end{array}$ & All bars & $\begin{array}{c}10 \text { bars, } 40 \text { in. } \\
(1,020 \mathrm{~mm}) \\
\text { above column } \\
\text { base }\end{array}$ & None & 1 tie \\
\hline Column 5 & $\infty$ & $\begin{array}{c}120 \mathrm{in} . \\
(3,050 \mathrm{~mm}) \\
\text { above column } \\
\text { base }\end{array}$ & $\begin{array}{c}64 \mathrm{in} . \\
(1,620 \mathrm{~mm}) \\
\text { above column } \\
\text { base }\end{array}$ & 2 bars & None & None & 0 tie \\
\hline
\end{tabular}

${ }^{\mathrm{a}}$ Values in this column refer to the number of ties removed during repairing.

A detailed description of the damage to the original columns is summarized in Table 1. Damage to each column included concrete cracking, cover concrete spalling, and core concrete crushing, as well as longitudinal reinforcement yielding. Damaged ties failed by yielding and, in some cases, subsequent straightening of the end hooks. Additionally, longitudinal bars buckled in Columns $1-4$, and two longitudinal reinforcing bars fractured in Column 1 near the base of the column at the northwest and southeast corners of the cross-section (see Fig. 1).

\section{Rapid Repair of Damaged Columns}

\subsection{Repair Materials}

In view of the short time frame for the rapid repair, the repair materials used were selected for ease of installation, compatibility with the other materials, and capability of achieving their desired strengths within the timeframe. A quickset repair mortar and unidirectional CFRP strengthening system were used in this study. The repair mortar was used to replace the removed damaged concrete, while the CFRP strengthening system was used to compensate for the loss in strength due to material degradation during the previous column tests.

The repair mortar was a shrinkage-compensating micro concrete that had high bond strength, high early strength, and self-compacting properties. Material properties provided by the manufacturer are given in Table 2 . The compressive strength was monitored by casting 2 in. $(51 \mathrm{~mm})$ cubes on the same day as replacing the removed concrete. The compressive strength was measured one day after casting, at test day, and at 28 days after casting. The compressive strength of the repair mortar measured at test date was nearly $5 \mathrm{ksi}$ (28 MPa) for each column.

The CFRP strengthening system consisted of unidirectional carbon fiber sheets. Putty was used to fill the voids on the column surface, while primer was use to facilitate the bond between the concrete and the CFRP system. The properties of the dry carbon fiber fabric provided by manufacturer were: tensile strength of $550 \mathrm{ksi}(3,800 \mathrm{MPa})$; tensile modulus of $33,000 \mathrm{ksi}(227 \mathrm{GPa})$; ultimate rupture strain of 0.0167 ; and nominal thickness of $0.0065 \mathrm{in}$. $(0.165 \mathrm{~mm})$ per ply. The carbon fiber was linear elastic.

Bond between the host concrete and externally applied CFRP is critical for flexural, shear, and torsional strengthening, so bond strength testing of the CFRP-to-concrete bond was performed in accordance with ASTM D7234 (2005). A representative sample of CFRP was bonded to the concrete surface that was prepared using the same techniques and at the same time as the CFRP application. The test was performed at the time of testing of the repaired column. For each column, the bond strength test results met the CFRP system manufacturer's and ACI 440.2R (2008) minimum specified bond strength of $200 \mathrm{psi}(1,380 \mathrm{kPa})$.

\subsection{Repair Procedure}

The entire repair process took approximately 30 manhours over three days and involved the following seven steps: (1) straightening the column; (2) removing loose 
Table 2 Repair mortar properties (provided by the manufacturer).

\begin{tabular}{|c|c|c|}
\hline Property & Results & Test Method \\
\hline Fresh wet density, $\mathrm{lb} / \mathrm{ft}^{3}\left(\mathrm{~kg} / \mathrm{m}^{3}\right)$ & $142(2,275)$ & ASTM C 138 \\
\hline $\begin{array}{l}\text { Compressive strength, psi (MPa); } 2 \text { in. } \\
\qquad(51 \mathrm{~mm}) \text { cubes }\end{array}$ & & ASTM C 109 \\
\hline 1 day & $2,500(17.2)$ & \\
\hline 7 days & $5,000(34.5)$ & \\
\hline 28 days & $6,000(41.4)$ & \\
\hline $\begin{array}{l}\text { Compressive strength, psi (MPa); } 3 \text { by } 6 \text { in. } \\
\text { ( } 76 \text { by } 152 \mathrm{~mm} \text { ) cylinders, at } 28 \text { days }\end{array}$ & $5,000(34.5)$ & ASTM C 39 \\
\hline Flexural strength, psi (MPa), at 28 days & $1,150(7.9)$ & ASTM C 348 \\
\hline $\begin{array}{l}\text { Slant shear bond strength, psi (MPa), at } \\
28 \text { days }\end{array}$ & $3,000(20.7)$ & ASTM C 882 (modified) \\
\hline Splitting tensile strength, psi (MPa), at 28 days & $500(3.4)$ & ASTM C 496 \\
\hline
\end{tabular}

concrete; (3) placing repair mortar; (4) preparing the column surface; (5) installing longitudinal and transverse CFRP; (6) arranging instrumentation; and (7) retesting repaired columns. The axial load was not applied during the repair procedure considering that shoring systems can be used to support the self-weight of the superstructure in practice during the repair. Straightening of the column was challenging and time-consuming due to limited equipment available in the lab; therefore the time for straightening was not included in the three-day period here. On the first day, the damaged loose concrete was removed and formwork erected, then quickset mortar was placed. The mortar was allowed to set approximately $12 \mathrm{~h}$ before the formwork was removed on the second day. Then the column surface was prepared for installation of the CFRP system. The surface was smoothed and corners were rounded with a hand grinder, and then putty and primer were applied. The longitudinal CFRP was applied, followed by transverse CFRP. The transverse CFRP was applied after the longitudinal CFRP to help preventing the debonding of the longitudinal CFRP from the host concrete. For the longitudinal CFRP, fibers were aligned along the longitudinal axis of the column. For the transverse CFRP, fibers were oriented transverse to the longitudinal axis of the column. Detailing of the CFRP systems is discussed in a subsequent section. No special technique was used to cure the CFRP system except for Columns 1 and 2 in which a plastic sheet and a small heater were used to facilitate curing because the temperature in the laboratory was unusually low. Cracks on the concrete surface outside the region with CFRP were not repaired. An unexpected delay occurred during the repair of Column 1, which resulted in testing on the 5th day.

\subsection{Test Setup and Loading Protocol}

The experimental setup is shown in Fig. 3. In the original tests, the columns were anchored to the strong floor with four DYWIDAG bars with 50 kips $(222 \mathrm{kN})$ prestressing force in each bar (Fig. 3a, b), which is discussed in Prakash et al. (2012). The system used to anchor the repaired columns to the strong floor was modified due to damage to the anchors. Two steel wide flange beams were used with two steel double channel beams to anchor the repaired column specimens (Fig. 3c, d). Because of the position of the wide flange beams and resulting space limitations, some of the instrumentation used in the original tests was not used in the repaired column tests.

The repaired columns were tested under the same initial combined loading effects as the original columns. Similar to the procedure used for testing the original columns, the testing procedure for repaired columns was initiated in force control and then continued in displacement control. In testing the original columns, testing shifted to displacement control when first yield of the reinforcing steel occurred (Prakash et al. 2012). For the repaired columns, yielding of the steel had occurred during the previous test, and monitoring the strain was not always possible due to damage to the strain gages mounted to the steel reinforcement. Therefore, testing was shifted to displacement control when significant reduction of the stiffness was observed. In addition, different procedures were used to maintain the torque-to-moment ratio $(\mathrm{T} / \mathrm{M})$ during the displacement control testing. In the original tests, an iterative feedback system was used to control the torque-to-moment ratio (Prakash et al. 2012), whereas in the present program, a trial-and-error method was used based on values recorded from the previous cycles. As a result, some differences existed in the loading protocol details.

\section{CFRP Layouts}

The CFRP layouts are summarized in this section. The CFRP design procedures will be described in detail elsewhere by the authors. In general, the externally bonded CFRP strengthening system for each damaged column was designed to restore the column strength in terms of shear, bending, and torsion associated with the peak load in the original test. It should be noted that in the case of a 


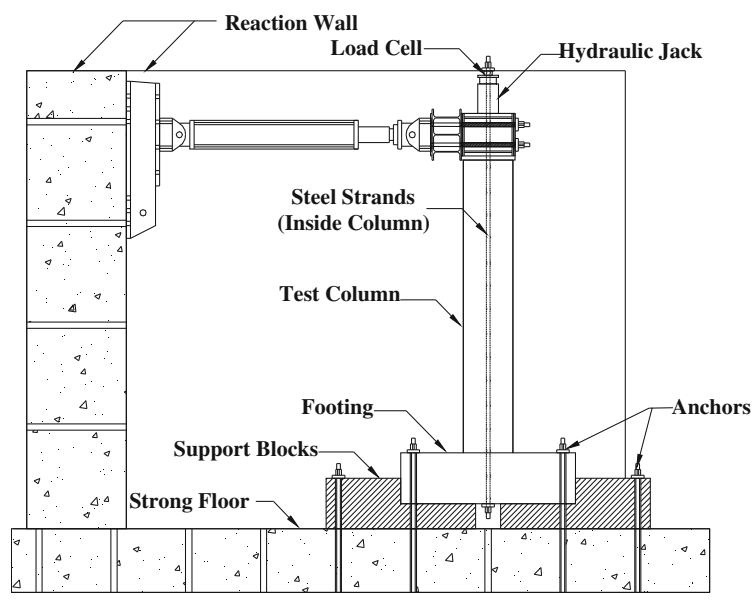

(a) Elevation View

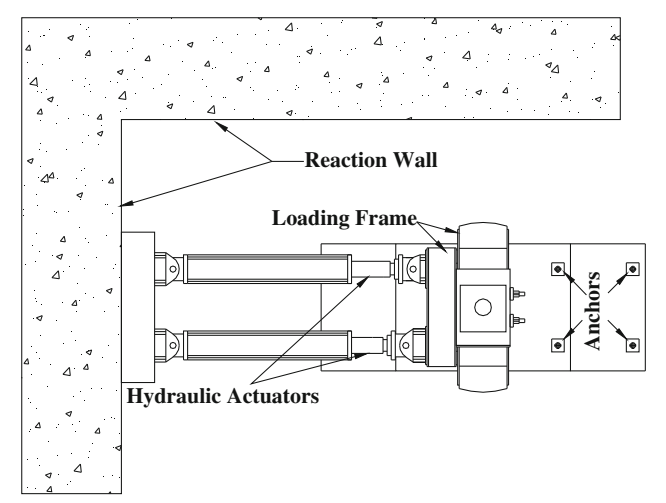

(b) Plan View

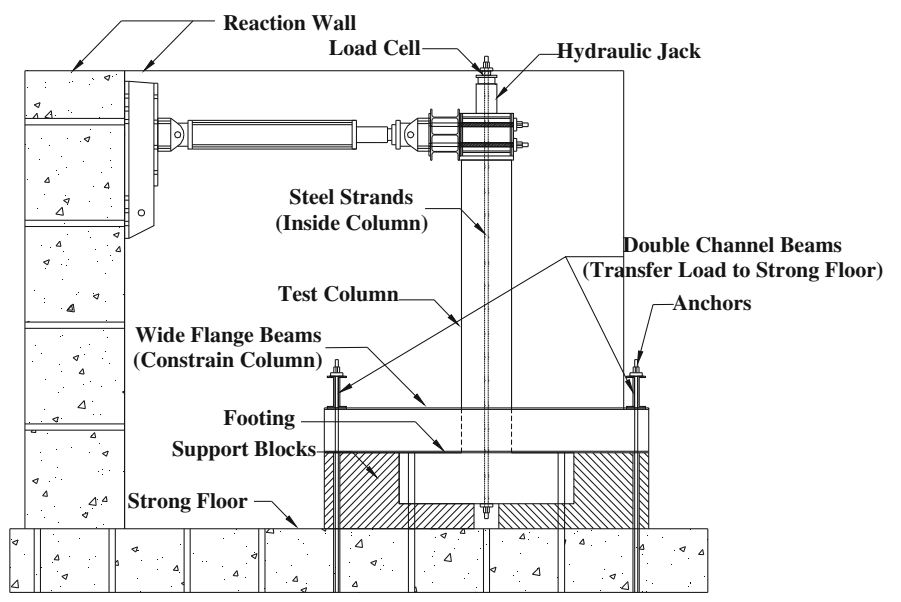

(c) Elevation View

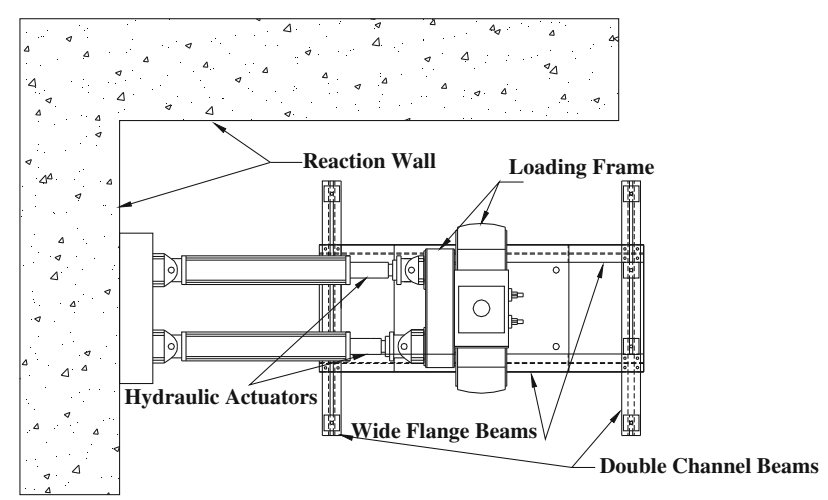

(d) Plan View

Fig. 3 Test setup for original and repaired columns.

permanent repair, the repair system should also be capable of restoring the ductility, although this aspect was not explicitly accounted for in the design due to the inclusion of torsion. The transverse CFRP wrap was designed to provide confinement to the concrete and to restore the strength in terms of torsion and shear, in which the CALTRANS provisions for RC column retrofit were used (2006, 2007). The longitudinal CFRP was designed to compensate for the flexural and torsional strength loss due to the damaged reinforcement and softened concrete. Interaction between bending and torsion was considered in the design (Park and Paulay 1975).

The CFRP layout for each repaired column is shown in Figs. 4 to 8 . Repaired columns are denoted in this paper with the extension “-R". The CFRP layout for each column was designed and detailed considering the nature of damage to the column, the damage location, and the peak applied loading. As a result, each column had a different repair region and CFRP layout. To maximize the time efficiency, only the regions of the column at and adjacent to the plastic hinge were repaired. Adjustments were made to the designs based on lessons learned during testing of previous repaired columns within the series as discussed below. (Repaired columns were repaired and tested in sequential order from Column 1-R to 5-R).

For Columns 1-R, 2-R, and 3-R, the repair regions were located in the lower half of the columns since the damage was concentrated near the base of the columns. This was the case because Columns 1, 2, and 3 were flexure dominant. The increasing number of transverse CFRP sheets at the bottom level of Column 3-R compared to Column 2-R, and Column 2-R compared to Column 1-R, is due to the fact that the damage in Columns $1-\mathrm{R}$ and $2-\mathrm{R}$ was concentrated near the base of the column, and damage did not spread to the adjacent region. Longitudinal CFRP was installed only on the north and south sides of Column 1-R because the column was subjected to uniaxial bending and no torsion, and because space limitations did not allow for installation of an appropriate anchorage system to anchor longitudinal sheets on the east and west faces. However, transverse CFRP splitting observed on the east and west sides at early stages of testing Column 1-R prompted the use of longitudinal CFRP sheets on all four sides of Columns 2-R and 3-R. Thus one longitudinal sheet was provided on the east and west sides that was anchored at the base by U-anchors, which required minimal space for installation. The longitudinal CFRP sheets on the north and south faces were anchored with an anchorage system consisting of a steel plate welded to a quarter-section of steel pipe reinforced with stiffeners and fastened to the concrete with threaded steel anchor rods that were embedded using a chemical adhesive. The anchorage system is sketched at the base of the columns in Figs. 4, 5 

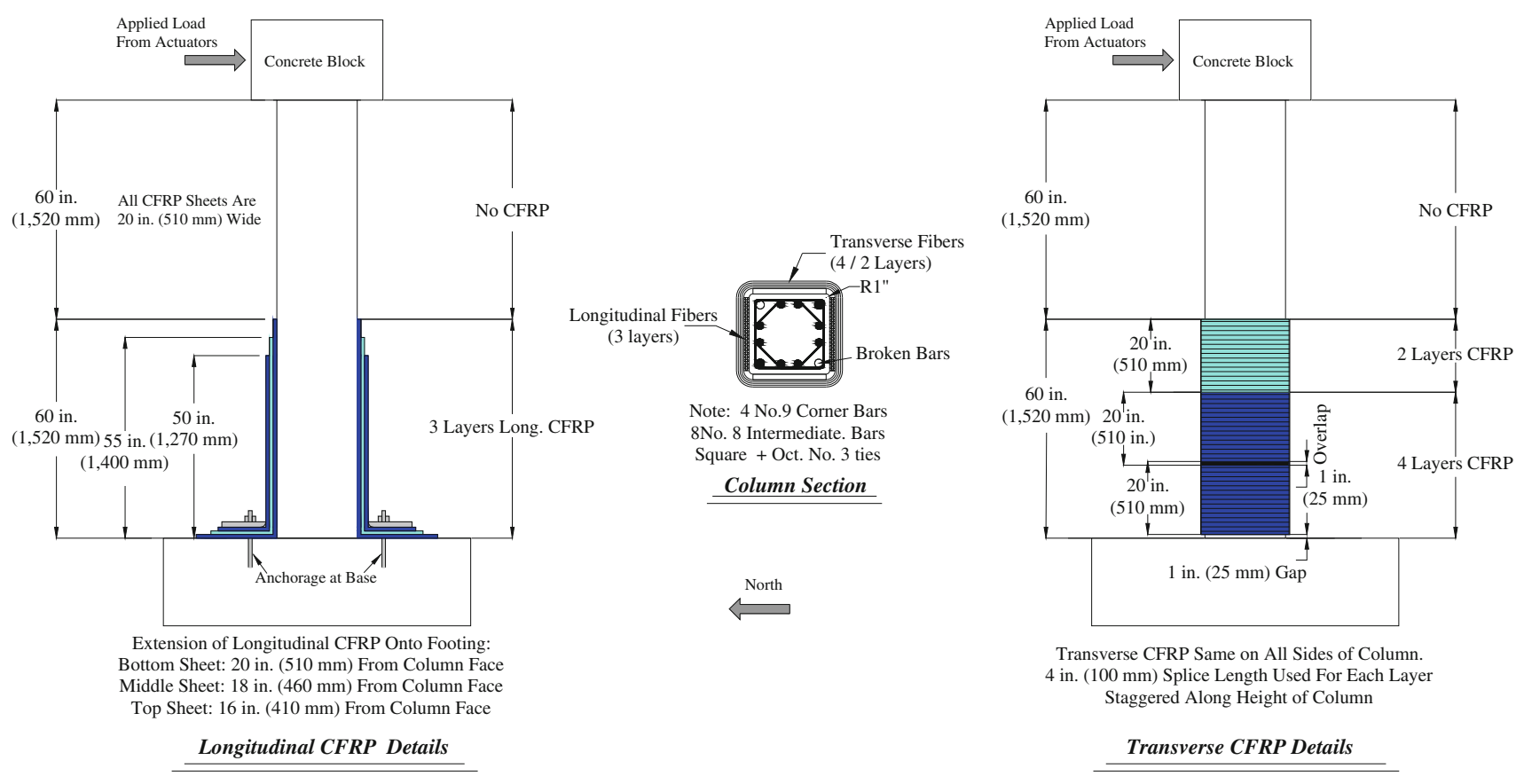

Fig. 4 CFRP layout for Column 1-R.
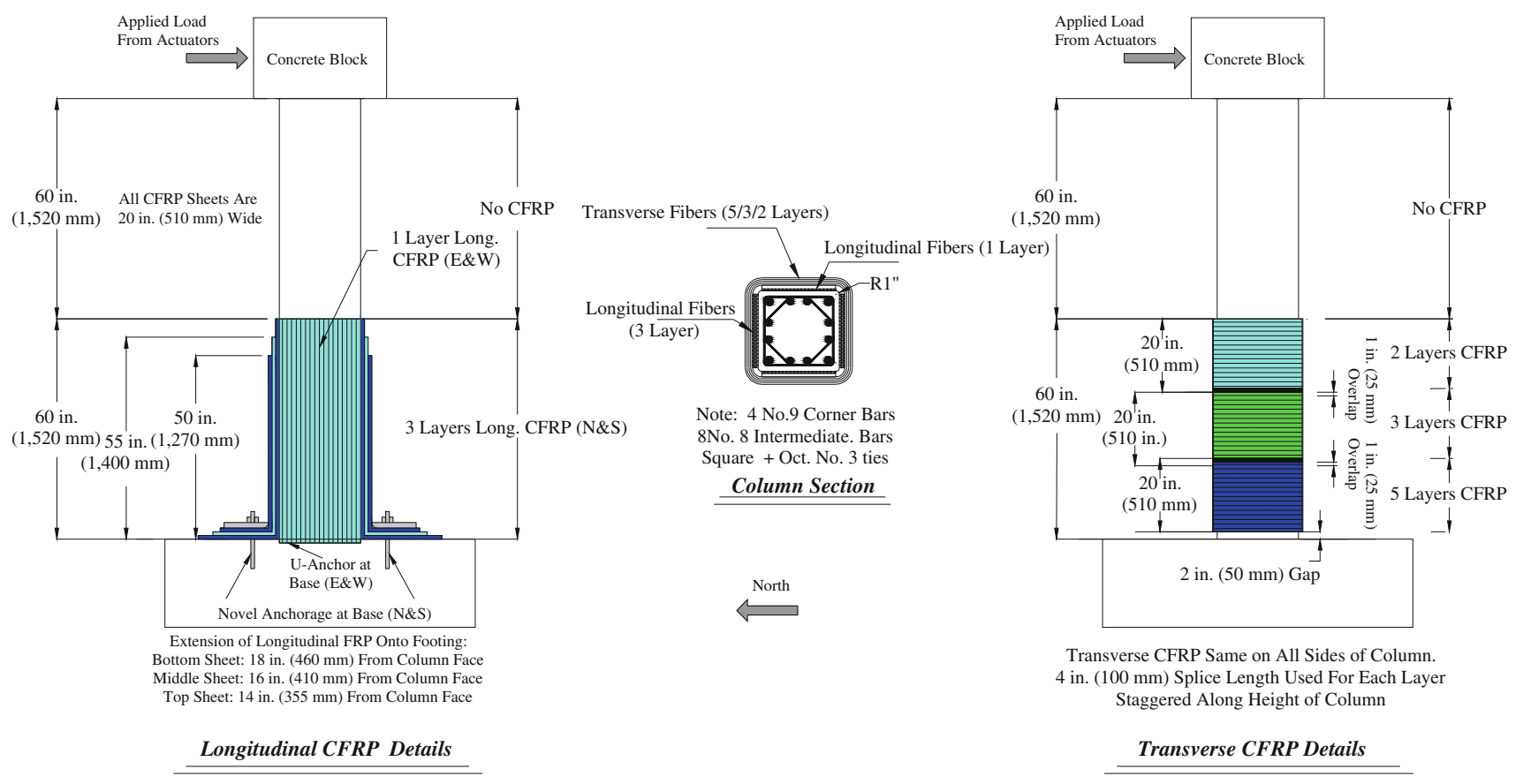

Fig. 5 CFRP layout for Column 2-R.

and 6. A photo of the anchorage system is shown in Fig. 9, and details of the anchorage system design are described by Grelle (2011).

For Columns 4-R and 5-R, the repair regions extended along most of the column length. Column 4 was repaired along most of its height except for the top $12 \mathrm{in.} \mathrm{(305} \mathrm{mm)}$ because of lack of damage in the top region as well as difficulty of applying formwork and placing the repair mortar along the full height of the column. However, shifting of the plastic hinge location of Column 4-R prompted the full height repair of Column 5-R.

\section{Test Results}

\subsection{Summary of Failure Modes}

The failure modes of the repaired columns are summarized in Table 3. Column 1-R experienced premature failure due to the detailing of the anchorage system used to anchor the longitudinal CFRP sheets to the base of the column (Grelle 2011). During testing, the top of the quarter-pipe section of the anchorage system came into contact with the CFRP system, which led to CFRP rupture on both the south and north sides of the column due to the bearing of the corner of the anchorage 


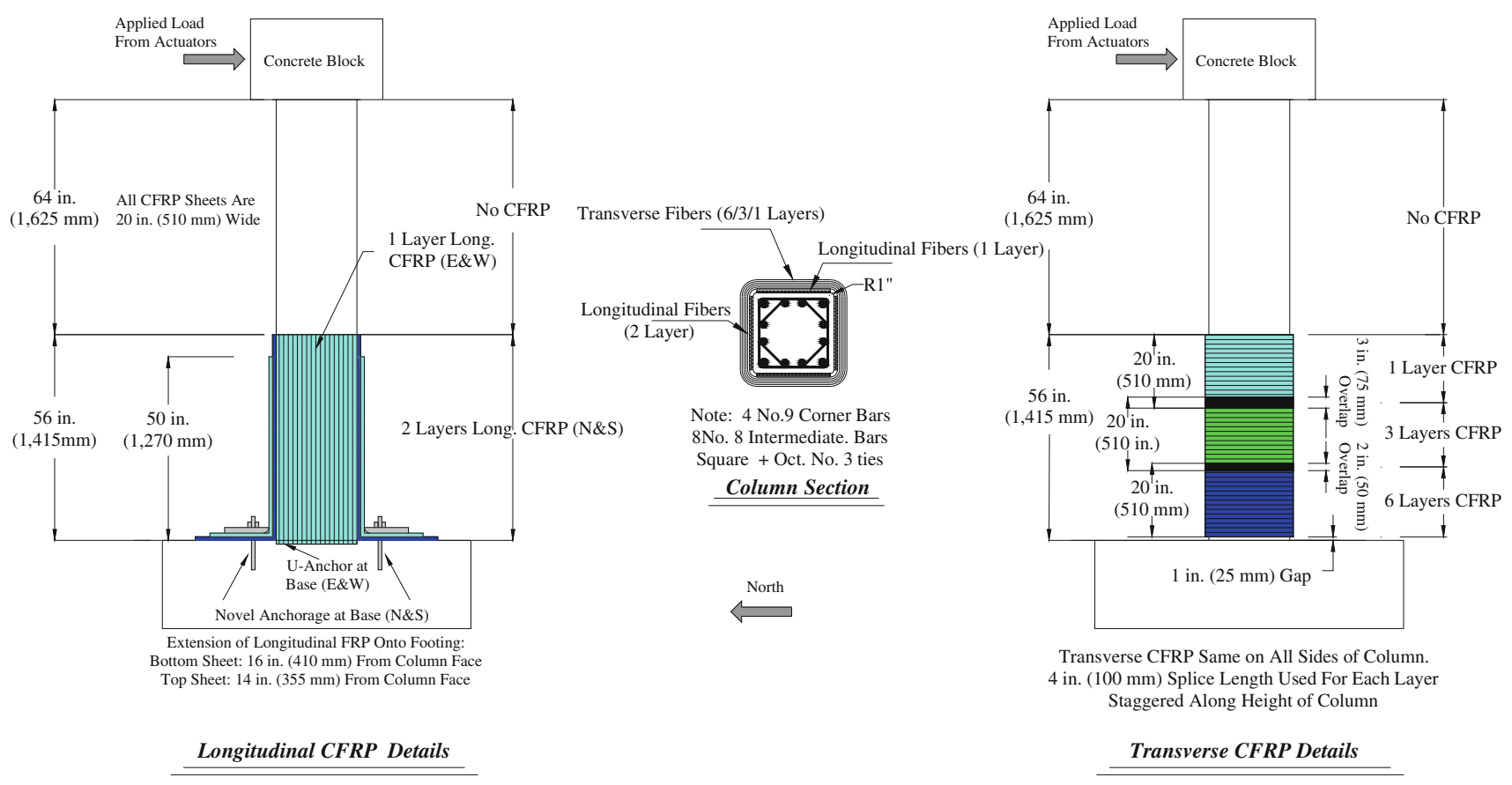

Fig. 6 CFRP layout for Column 3-R.

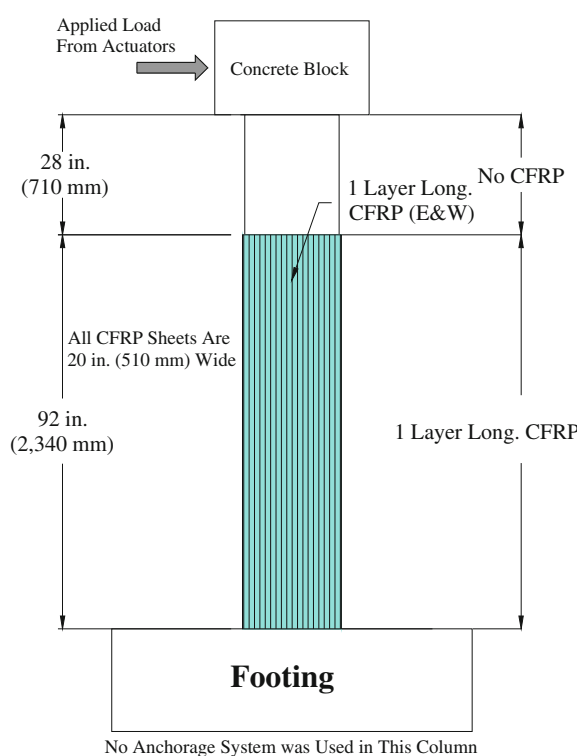

Longitudinal CFRP Details
Transverse Fibers (4/3/2/1 Layers)

(1 Labinal Fibers (1 Layer)

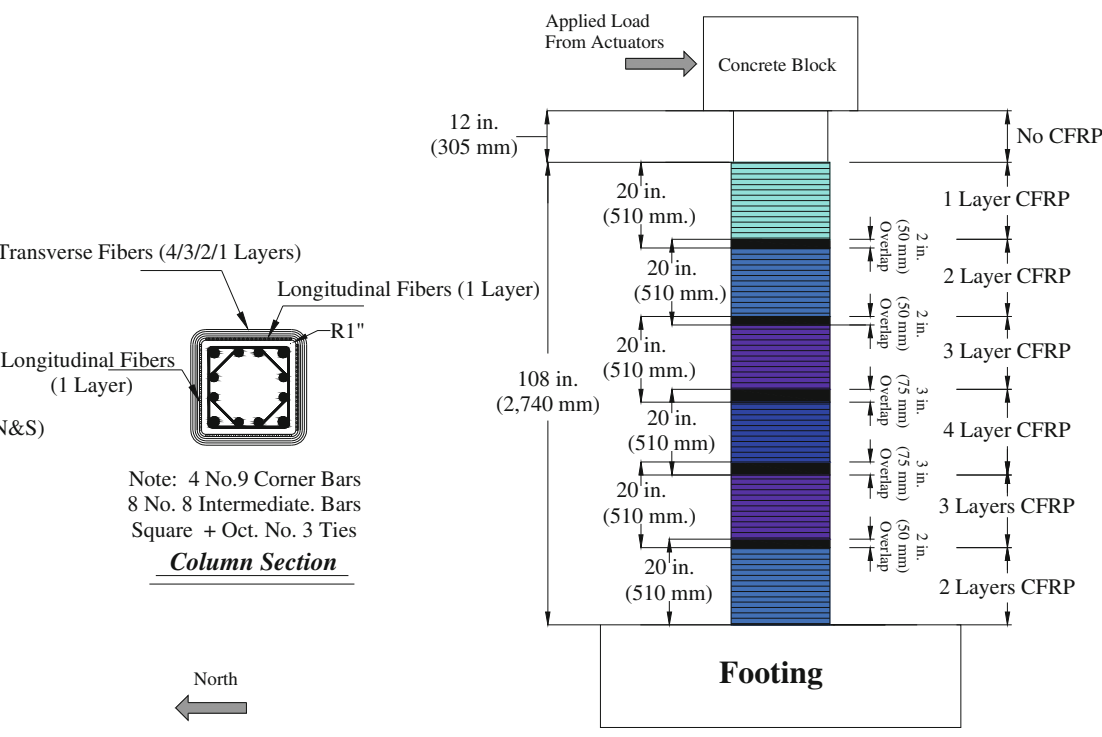

Transverse CFRP Same on All Sides of Column. 4 in. $(100 \mathrm{~mm})$ Splice Length Used For Each Layer Staggered Along Height of Column

Fig. 7 CFRP layout for Column 4-R.

system. It must be noted that because Column 1 had fractured longitudinal bars, the repair needed to compensate for the strength loss of the fractured bars. This resulted in a large demand on the longitudinal CFRP relative the other repaired columns, and also resulted in a large force in the CFRP that needed to be anchored to the base at the critical section for bending moment. Column 2-R, which had the plastic hinge at the base of column after the previous test similar to Column 1, failed due to CFRP rupture and crushing of concrete in plastic hinge region near the base of the column. No further damage was observed in the unrepaired region of Column 2-R. Also, the detailing problems with the anchorage system were avoided by maintaining a gap between the repaired column and the anchorage system. For Column 3-R, the test was terminated due to limitations of the actuators. No damage was observed in the repaired region; however the plastic hinge relocated just above the repaired region. The concrete cover just beyond the repaired region spalled off, and the cover spalling progressed upwards until testing was terminated. The plastic hinge was also relocated in Column 4-R from the location in Column 4, For Column 4-R, the plastic hinge shifted to the unrepaired region just above the repaired region. The failure mode was concrete 


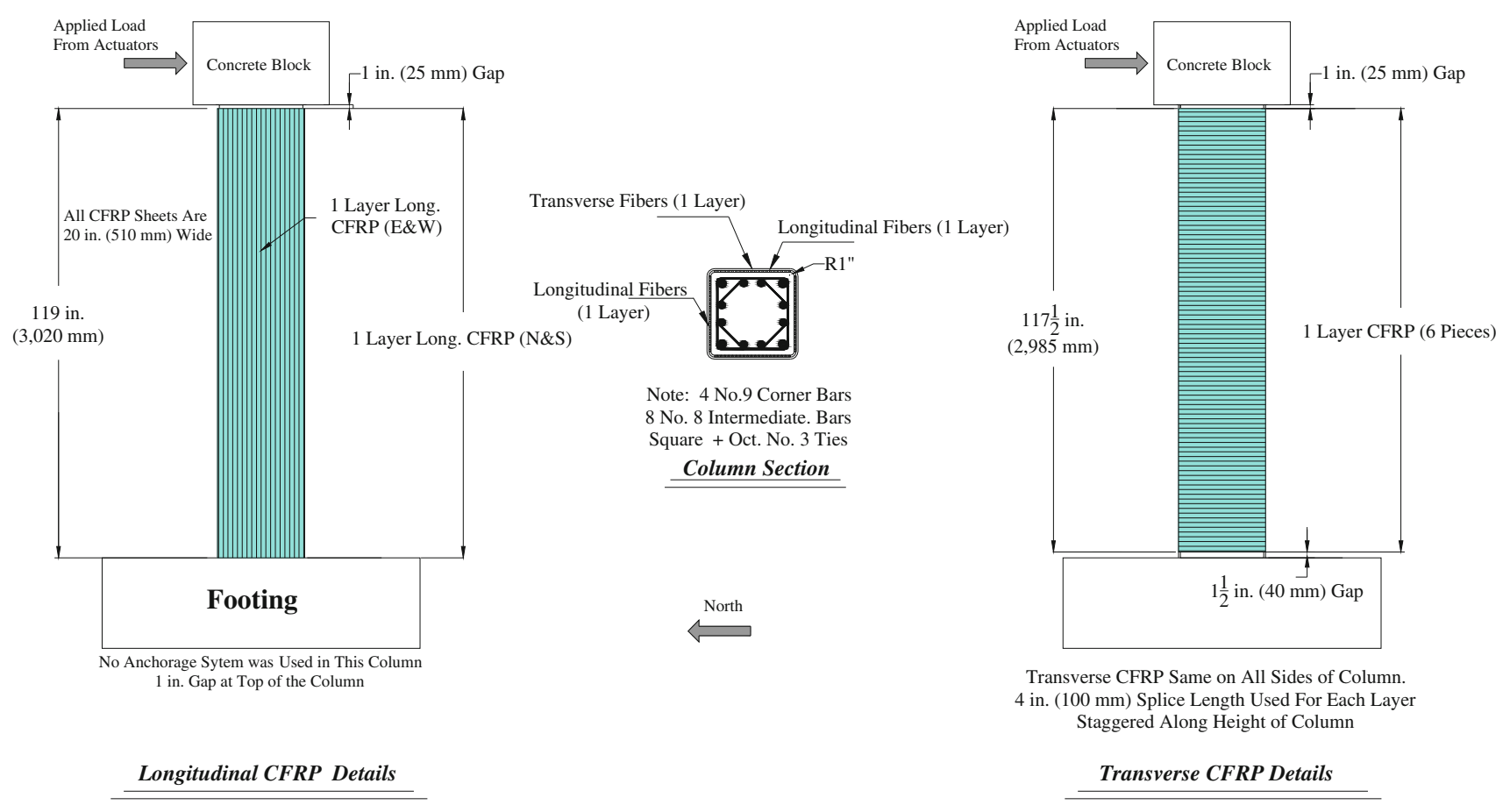

Fig. 8 CFRP layout for Column 5-R.

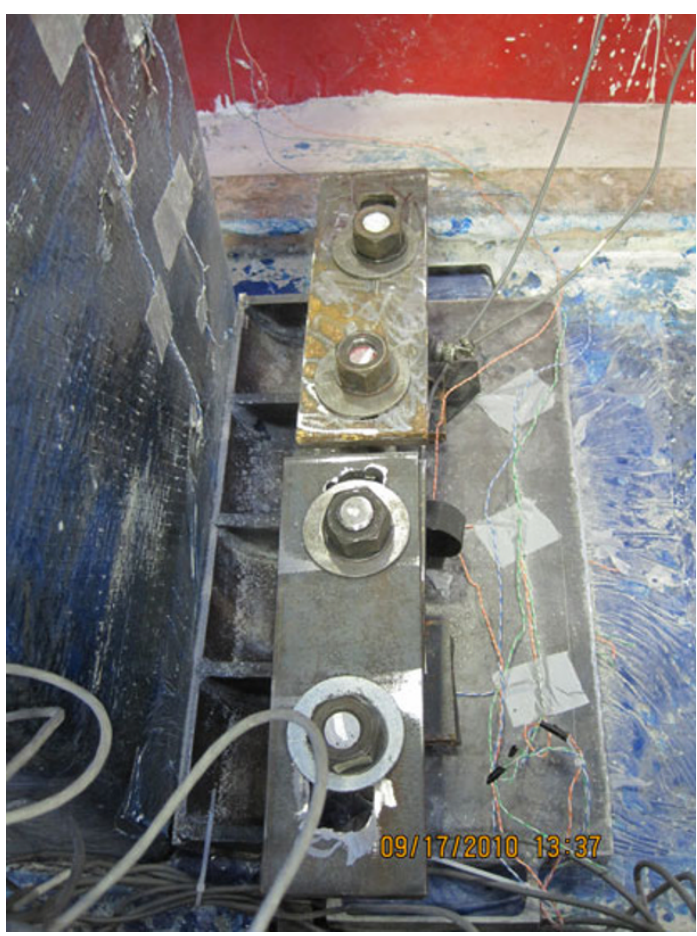

Fig. 9 Novel anchorage system.

crushing in the unrepaired region followed by CFRP rupture near the unrepaired region. The failure mode of Column 5-R was rupture of the CFRP. Rupture of the external CFRP on Column 5-R first occurred at the south-west corner of the column approximately $65 \mathrm{in}$. (1,650 $\mathrm{mm})$ above the column base, which coincides with the interface of the unrepaired concrete and the newly placed repair mortar. Rupture progressed to the upper west side of the column, and then to the lower south side. Finally, the ruptured CFRP peeled away with a thin layer of concrete bonded underneath, and crushed mortar fell out.

\subsection{General Behavior of Repaired Columns}

The general response of each repaired column relative to the corresponding original column is described in this section. The measured load-displacement and torque-twist relationships of the repaired columns compared to the corresponding original columns are shown in Figs. 10 to 14 , in which both the hysteresis and envelope responses are provided. As illustrated in the figures, the repaired columns behaved asymmetrically in the positive and negative cycles. This response can be attributed to the unsymmetrical damage in the original column, the unsymmetrical removal and replacement of loose concrete during the repair procedure, and possibly some original displacement at the beginning of testing the repaired columns, which was due to the fact that the repaired column was not perfectly straightened.

The measured lateral load and displacement in Column $1-\mathrm{R}$ did not reach that of Column 1 , which is due to premature failure associated with longitudinal CFRP anchorage as discussed in the previous section. A moment-curvature analysis of the repaired cross-section confirms that the lateral load associated with the predicted moment capacity after failure of the longitudinal CFRP was close to the peak lateral load measured during the test. It must be noted that anchorage of externally bonded longitudinal CFRP sheets is a crucial issue to ensure that the tensile force can be developed at the critical section. When the plastic hinge is located near a joint, the situation is even more complicated by the interaction between the column and the anchorage system, which was the situation of Column 1-R. Therefore careful attention must be paid to detailing of both the FRP and its anchorage system.

Figures 11 and 12 show that both the flexural strength and ducitlity of Columns 2-R and 3-R were mainly restored to 
Table 3 Summary of failure modes of repaired columns.

\begin{tabular}{|c|c|c|}
\hline Repaired column & Failure mode & \\
\hline Column 1-R $(\mathrm{T} / \mathrm{M}=0)$ & $\begin{array}{l}\text { Premature failure related to the detailing of } \\
\text { the longitudinal CFRP anchorage system, } \\
\text { followed by fracture of two additional } \\
\text { longitudinal reinforcing steel bars }\end{array}$ & \multirow[t]{3}{*}{ Flexure dominant } \\
\hline Column 2-R $(\mathrm{T} / \mathrm{M}=0.2)$ & $\begin{array}{l}\text { Rupture of CFRP (flexure), crushing of } \\
\text { concrete in the repaired region }\end{array}$ & \\
\hline Column 3-R $(\mathrm{T} / \mathrm{M}=0.4)$ & $\begin{array}{l}\text { Testing terminated due to limitations } \\
\text { of the actuators }\end{array}$ & \\
\hline Column 4-R $(\mathrm{T} / \mathrm{M}=0.6)$ & $\begin{array}{l}\text { Crushing of concrete in the unrepaired } \\
\text { region (torsion) followed by CFRP rupture } \\
\text { next to the unrepaired region }\end{array}$ & \multirow[t]{2}{*}{ Torsion dominant } \\
\hline Column 5-R $(\mathrm{T} / \mathrm{M}=\infty)$ & $\begin{array}{l}\text { Rupture of CFRP, crushing of concrete } \\
\text { (torsion) }\end{array}$ & \\
\hline
\end{tabular}
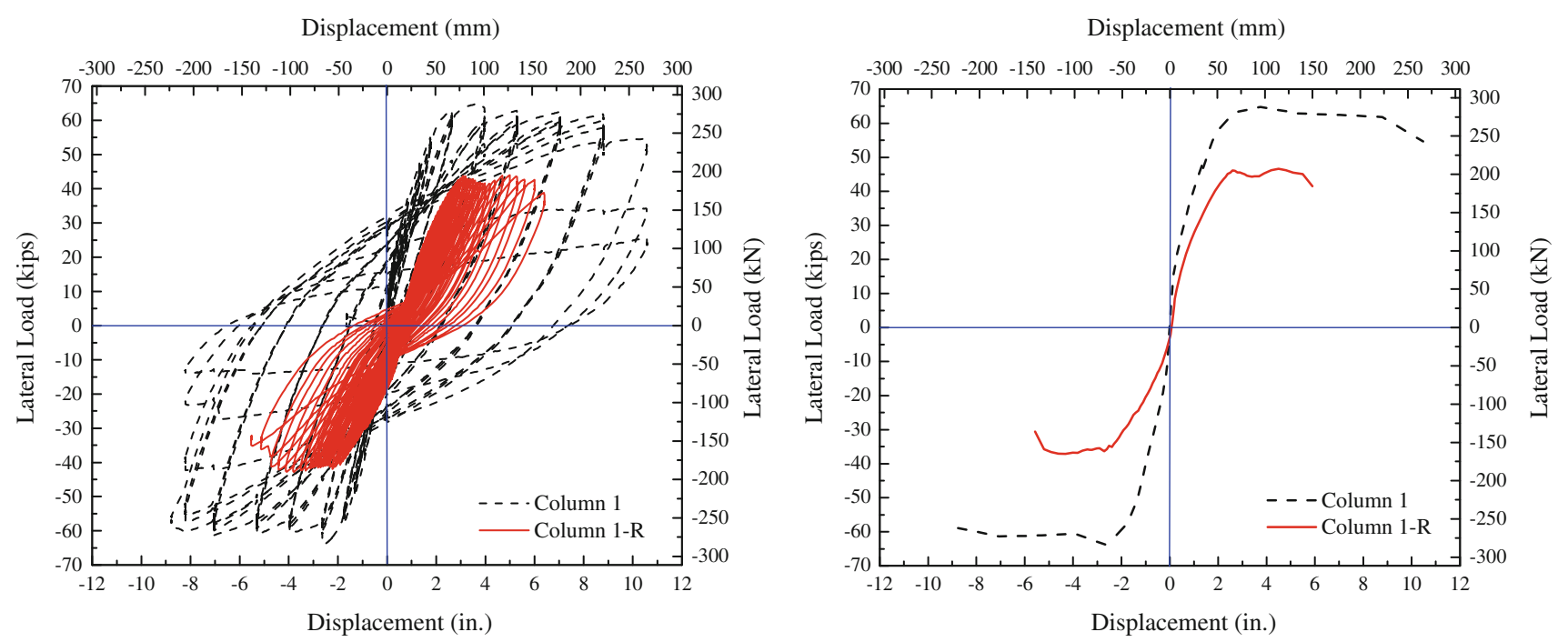

Fig. 10 General behavior of Column 1-R compared to Column 1

Columns 2 and 3, although the maximum torque of Column 2-R did not reach that of original column. Similarly for Column 4-R, Fig. 13 shows that the torsional strength was improved compared to Column 4 , but the measured lateral load and displacement did not reach the original state. To explain the differences in bending and torsional strength restoration for each repaired column, the difference in the loading protocol details between the repaired column and corresponding original column must be noted. As discussed previously, it was difficult to maintain the torque-to-moment ratio after shifting to displacement control, which resulted in the applied load with different torque-to-moment ratios for the repaired and original columns. For instance Fig. 15 shows the torque-to-moment ratios (T/M) for the applied load on Column 4-R and Column 4. The torque-to-moment ratio of Column 4 reduced significantly after shifting from load control to displacement control at a lower load level compared to Column 4-R. This resulted in higher bending moment in Column 4 compared to Column 4-R, since this bending moment was reached at a lower torque compared to
Column 4-R. Therefore, it can be concluded that the bending-torque interaction played a role in the level of strength restored.

Comparison of the applied torque-twist envelopes of Column 5 and Column 5-R in Fig. 14 indicates that the torsional strength and twist at maximum torque were enhanced by the repair. For Column 5, the torsional strength reduced rapidly after the maximum torque was achieved because the core concrete crushed and thus could not provide further torsional resistance. The post-peak response of Column 5-R was characterized by a reduction in torsional strength with increasing applied torque, but not as rapidly as that of Column 5. This phenomenon can be explained in part by the confinement provided by the transverse CFRP wrap.

In general, Figs. 10 to 14 also show that the rate of stiffness deterioration of the repaired columns under large reversed cyclic loading was lower than that of the corresponding original columns. However, the initial stiffness of repaired columns was lower than that of corresponding original columns. 

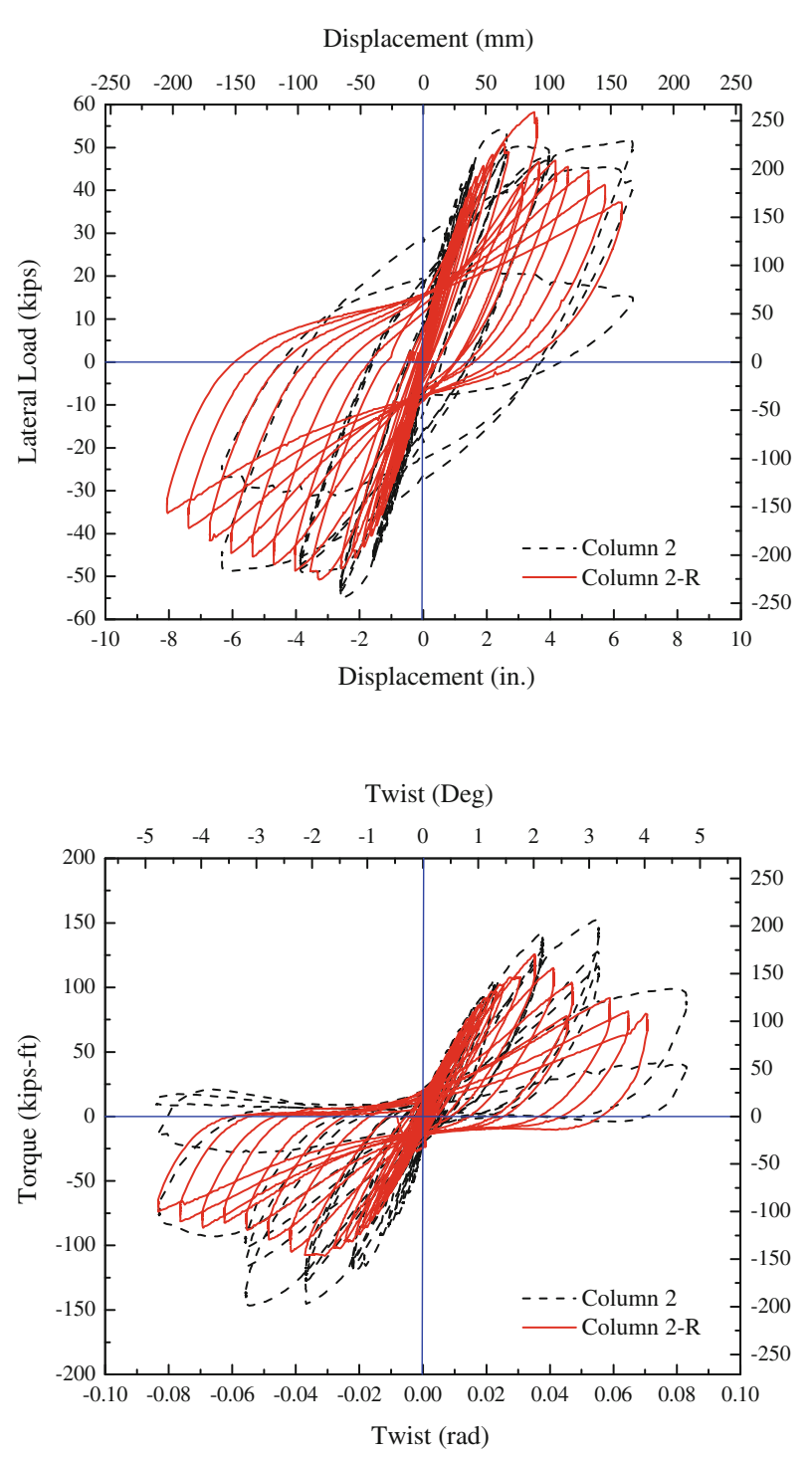

(b) (a)

Displacement (mm)
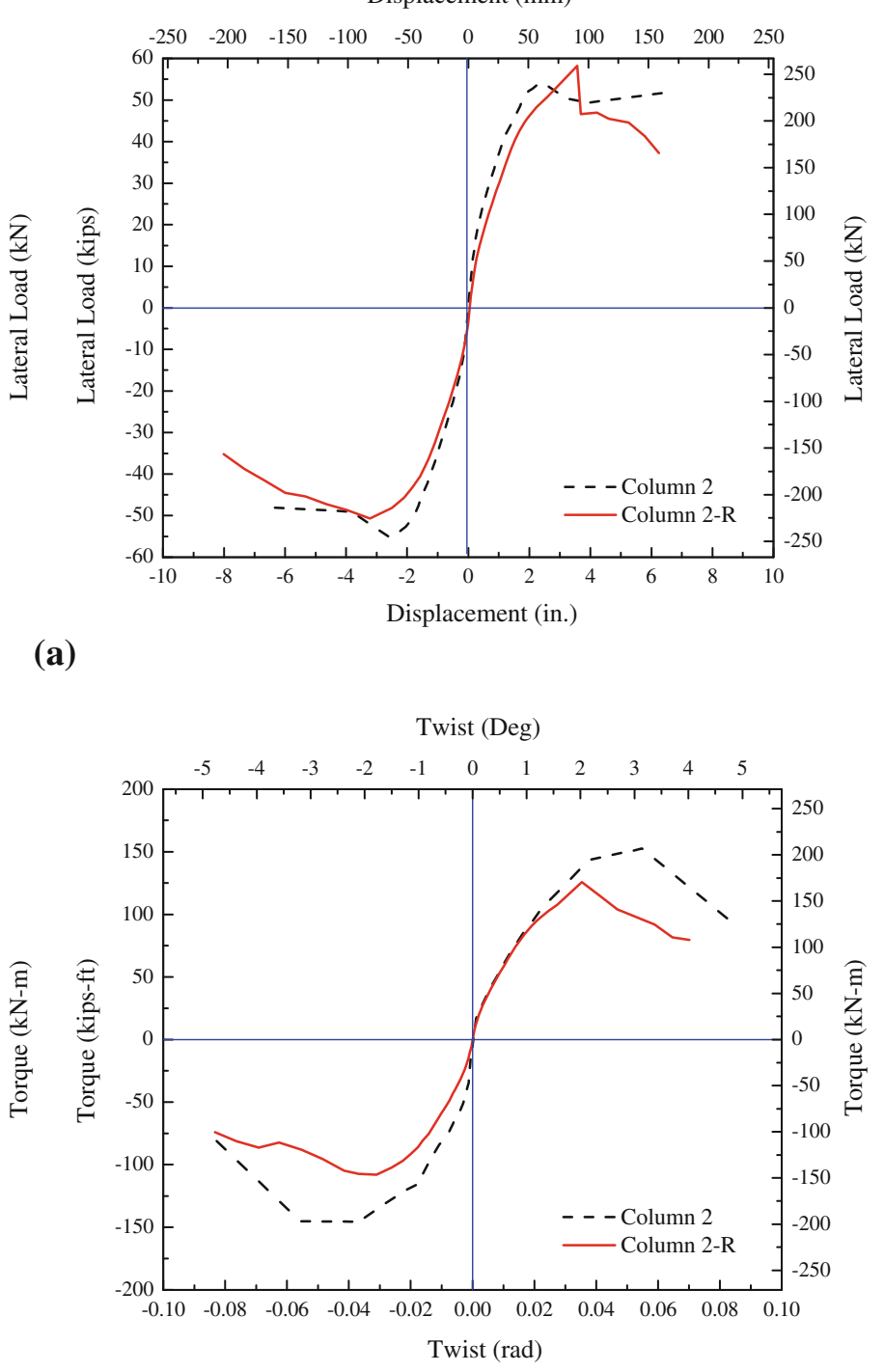

Fig. 11 General behavior of Column 2-R compared to Column 2. a Bending behavior. b Torsional behavior.

\subsection{Evaluation of the Repair Technique}

Comparison of the repaired column performances in this study is complicated by the different damage conditions of the corresponding original columns and the different repair profiles. Thus non-dimensional response indices were developed to compare the repaired column to the corresponding original column in terms of strength, stiffness, and ductility, which were the extension of previous work by Vosooghi and Saiidi (2013). The indices were then used to compare the performance of the repaired columns.

\subsubsection{Strength Index}

The strength of a column is defined as the maximum measured applied load during the test (Vosooghi and Saiidi 2009). The ratio of the repaired column strength to the original column strength is defined as the strength index STRI, which was determined by Eq. (1).

$$
\begin{aligned}
\text { STRI } & =\frac{V_{r}}{V_{o}} \\
& =\left(\frac{T_{r}}{T_{o}}\right)
\end{aligned}
$$

$V_{r}\left(T_{r}\right)$ and $V_{o}\left(T_{o}\right)$ in Eq. (1) represent the maximum lateral load (torque moment) measured in the repaired and original columns, respectively.

The strength indices for the columns are provided in Fig. 16, which illustrates that the repair method is effective in restoring the bending and/or torsional strength. The flexural strength restoration ranged from 63 to $111 \%$, and torsional strength restoration ranged from 83 to $118 \%$. Although Column 1-R was restored to $75 \%$ of its original flexural strength, the results can be misleading since the strength restoration was limited by the flexural capacity of the repaired cross-section section with fractured bars, because the longitudinal CFRP failed prematurely. For Columns 2-R, 3-R, and 4-R, which were subjected to combined bending and torsion, either the flexural strength, the torsional strength, or both, were fully restored. Bendingtorque interactions played a role in the level of bending and torsional strength restored as discussed in the previous sections. For Column 5-R subjected to pure torsion, the torsional strength was fully restored. 


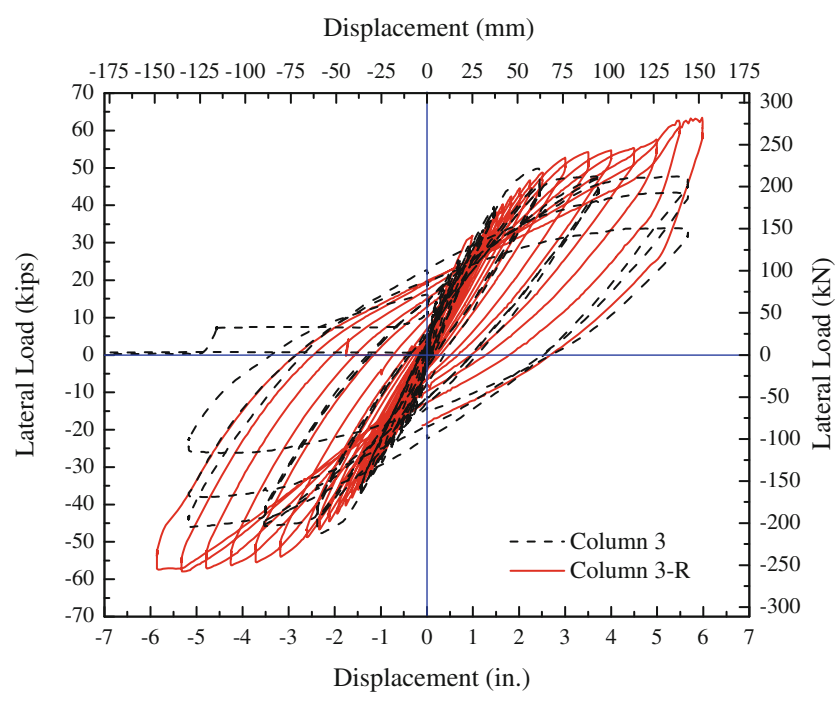

(a)

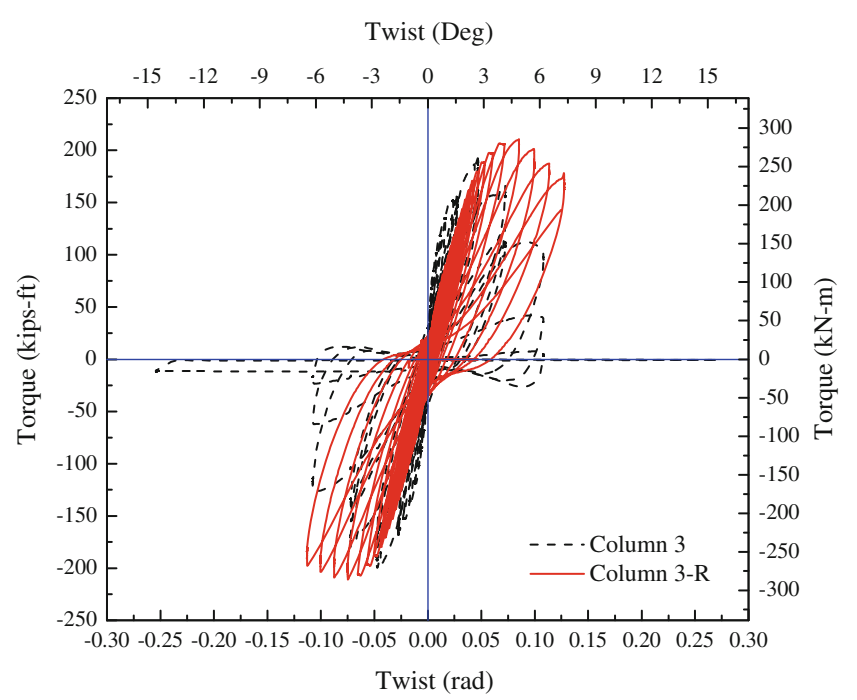

(b)
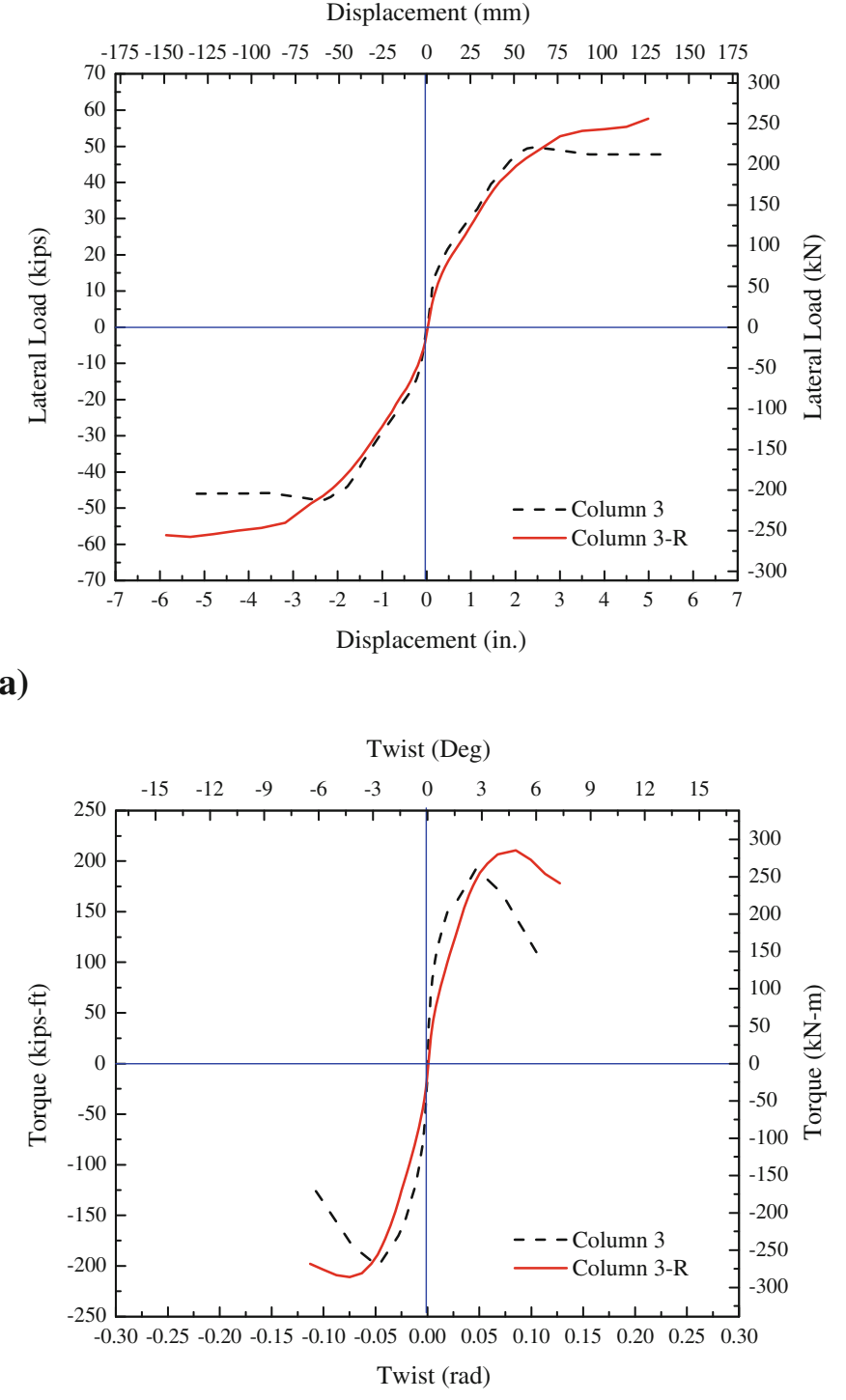

(a)

Fig. 12 General behavior of Column 3-R compared to Column 3. a Bending behavior. b Torsional behavior.

\subsubsection{Stiffness Index}

The stiffness of columns can be expressed by the initial stiffness and the general service stiffness, which were determined by the following methods. The initial stiffness was determined by the ratio of the summation of absolute values of positive and negative peak lateral load (torque for torsion) in the first cycle of the test to the summation of corresponding absolute values of positive and negative displacement (twist for torsion) (Jing et al. 2007), which was calculated by Eq. (2). The ratio of the repaired column initial stiffness to the original column initial stiffness is defined as the stiffness index $S T F I_{1}$, which was computed by Eq. (3).

$$
\begin{aligned}
& K_{i}=\frac{V_{p 1}+V_{n 1}}{D_{p 1}+D_{n 1}} \\
& =\left(\frac{T_{p 1}+T_{n 1}}{T W_{p 1}+T W_{n 1}}\right) \\
& S T F I_{1}=\frac{K_{i r}}{K_{i o}}
\end{aligned}
$$

In Eq. (2), $V_{p l}\left(T_{p l}\right)$ is the measured positive peak lateral load (torque moment) during the first cycle, and $D_{p I}\left(T W_{p I}\right)$ is the corresponding lateral displacement (twist). $V_{n l}\left(T_{n l}\right)$ is the absolute value of measured negative peak lateral load (torque), and $D_{n 1}\left(T W_{n 1}\right)$ is the absolute value of the corresponding lateral displacement (twist).

The initial stiffness indices for the repaired columns are illustrated in Fig. 17. The initial bending stiffness indices ranged from 39 to $112 \%$, and initial torsional stiffness indices ranged from 32 to $81 \%$. With the exception of the bending stiffness of Column 4-R/4, the initial stiffness of the repaired columns was lower than that of the corresponding original columns. This reduction in initial stiffness is due to the unrepaired cracked portions of the repaired columns and material degradation during the original tests.

The general service stiffness index was determined based on an idealized envelope representing an elasto-plastic curve (Vosooghi et al. 2008). For the original columns, the envelopes were idealized by setting the initial slope to pass through the first yield point and adjusting the plastic portion 
Displacement ( $\mathrm{mm})$

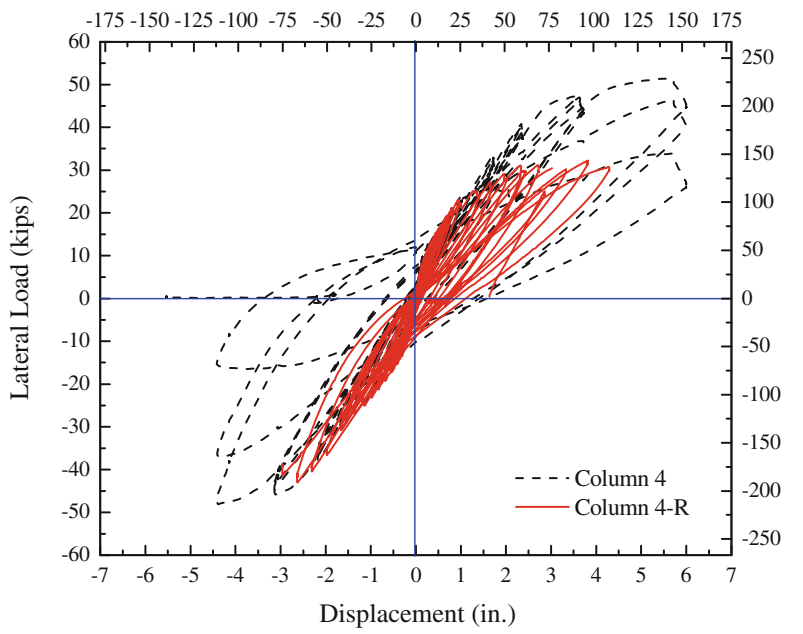

(a)

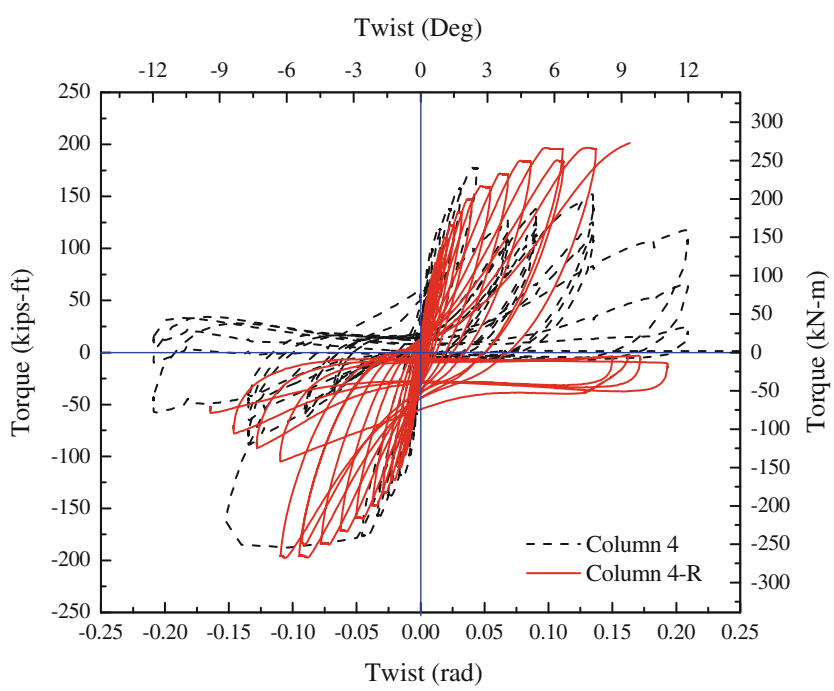

(b)
Displacement ( $\mathrm{mm})$
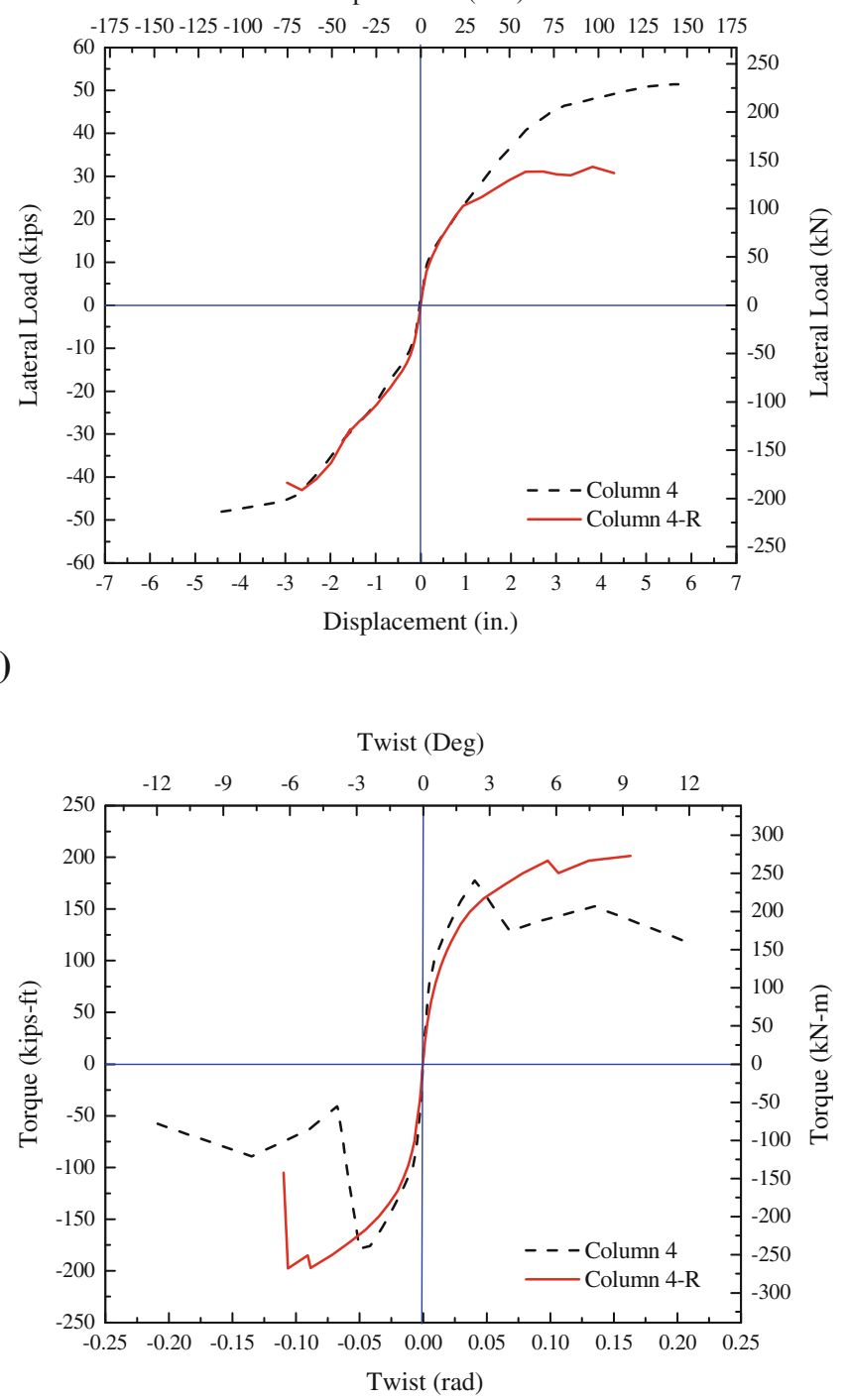

Fig. 13 General behavior of Column 4-R compared to Column 4. a Bending behavior. b Torsional behavior.
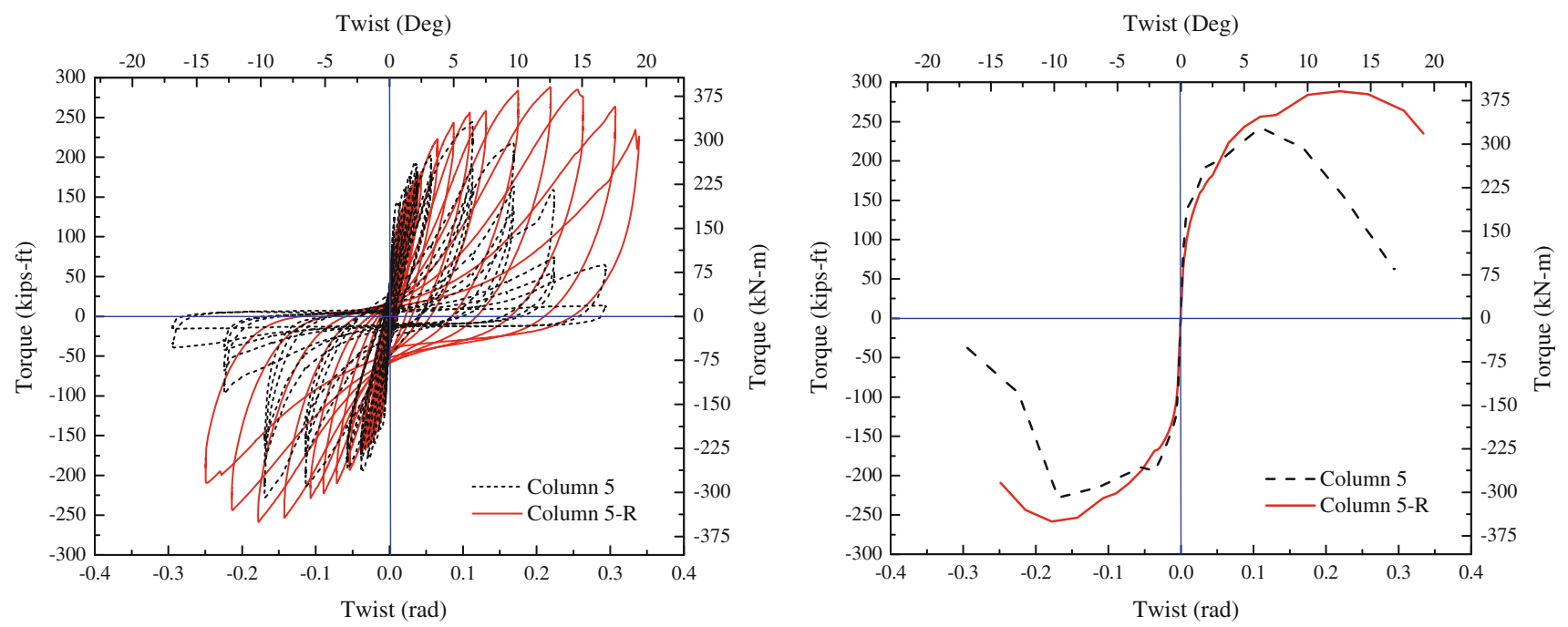

Fig. 14 General behavior of Column 5-R compared to Column 5. 


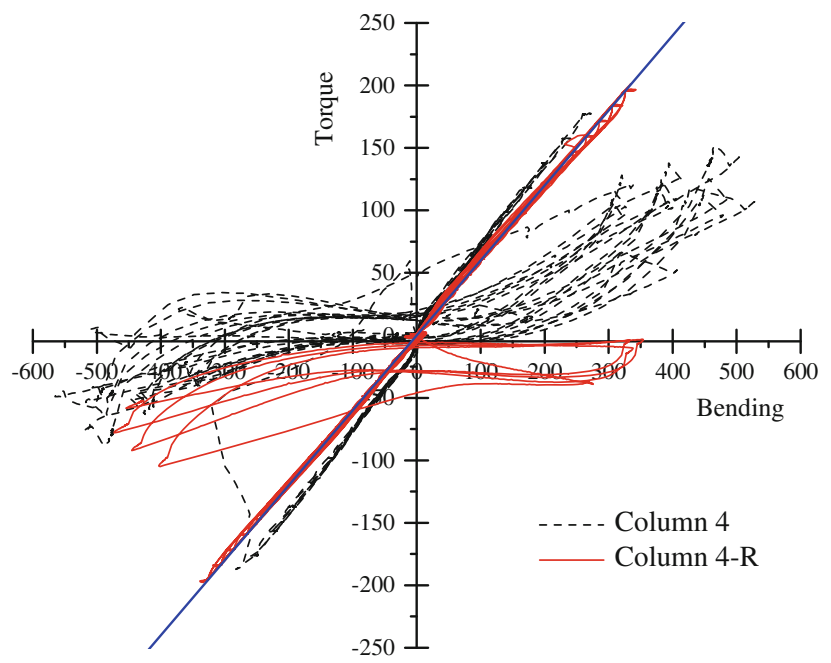

Fig. 15 Torque-to-moment ratios for Column 4 and Column 4-R.

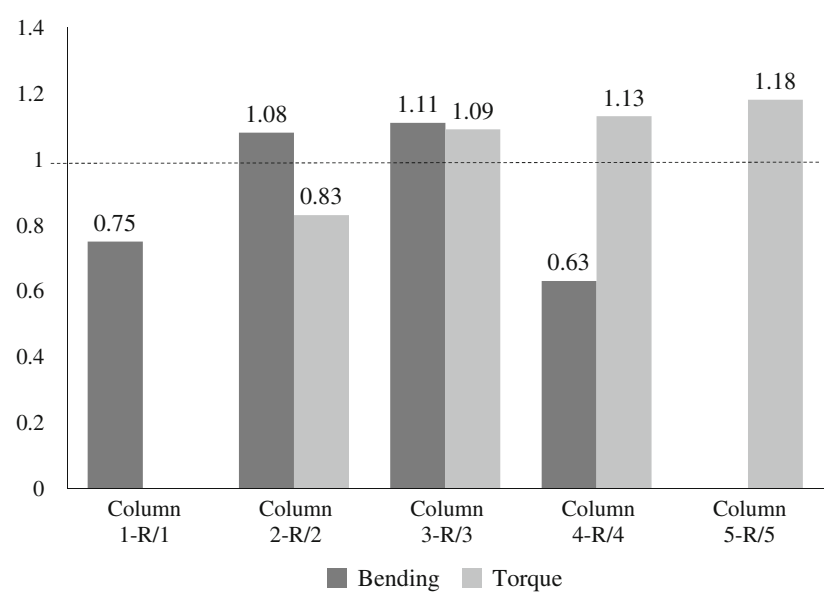

Fig. 16 Strength indices for repaired columns.

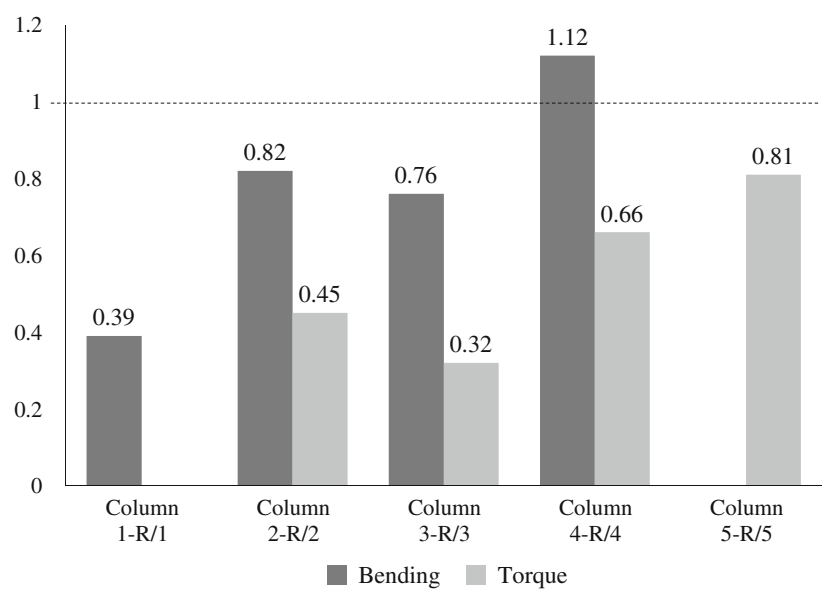

Fig. 17 Stiffness indices of initial state for repaired columns.

so that areas under the measured curve and idealized curve were equal. For the repaired columns, the elastic part of the idealized curve was obtained by connecting the origin to the point on the measured envelope at which the applied load (torsional moment) was one-half of the peak measured value. The yield level was established by equalizing the area between the measured and idealized curves. The idealizations of the envelopes of the original and repaired columns are illustrated in Fig. 18.

The general service stiffness index $S T F I_{2}$ is defined as the ratio of the service stiffness of the repaired column $K_{r}$ to that of the original column $K_{o}$ as shown in Eq. (4). The service stiffnesses $K_{r}$ and $K_{o}$ are determined from the ratio of the plastic base shear (torque) to the effective yield displacement (twist), which were obtained from the idealized curves (see Fig. 18).

$$
\mathrm{STFI}_{2}=\frac{K_{r}}{K_{o}}
$$

The general service stiffness indices of the repaired columns are summarized in Fig. 19. The general service stiffness indices for bending ranged from 85 to $189 \%$, and general service stiffness indices for torsion ranged from 69 to $138 \%$.

It should be noted that the general service stiffness indices for the repaired columns are dependent on the idealization of the measured envelopes of both original and repaired columns. Results are sensitive to assumputions used in developing the idealized curves. Thus these index values are presented herein to compare the global behaviors of the repaired and corresponding original columns. Also, the torque-bending interaction should be kept in mind in evaluating these indices. In general, the general service stiffness was restored more effectively than the initial stiffness.

\subsubsection{Ductility Index}

The ductility index $D I$ is defined as the ratio of the ductility capacity of the repaired column $D_{r}$ to that of the original column $D_{o}$ (see Eq. (5)). The ductility capacity is defined as the ratio of the ultimate displacement (twist) to the effective yield displacement (twist), which can be obtained from the idealized curves in Fig. 18.

$$
D I=\frac{D_{r}}{D_{o}}
$$

The ductility indices in terms of both bending and torsion are illustrated in Fig. 20. The ductility indices for bending ranged from 68 to $250 \%$, and for torsion ranged from 69 to $170 \%$.

Similar to the general service stiffness indices, the ductility indices for the repaired columns are dependent on the idealization of the measured envelopes of both original and repaired columns. However, results are encouraging and suggest that the ductility can be restored to an extent that can meet the needs of a temporary repair and allow emergency service use after an earthquake. More work is needed to determine whether this method can be used for permanent repair, in which case the ductility should be considered in design and should be fully restored. 

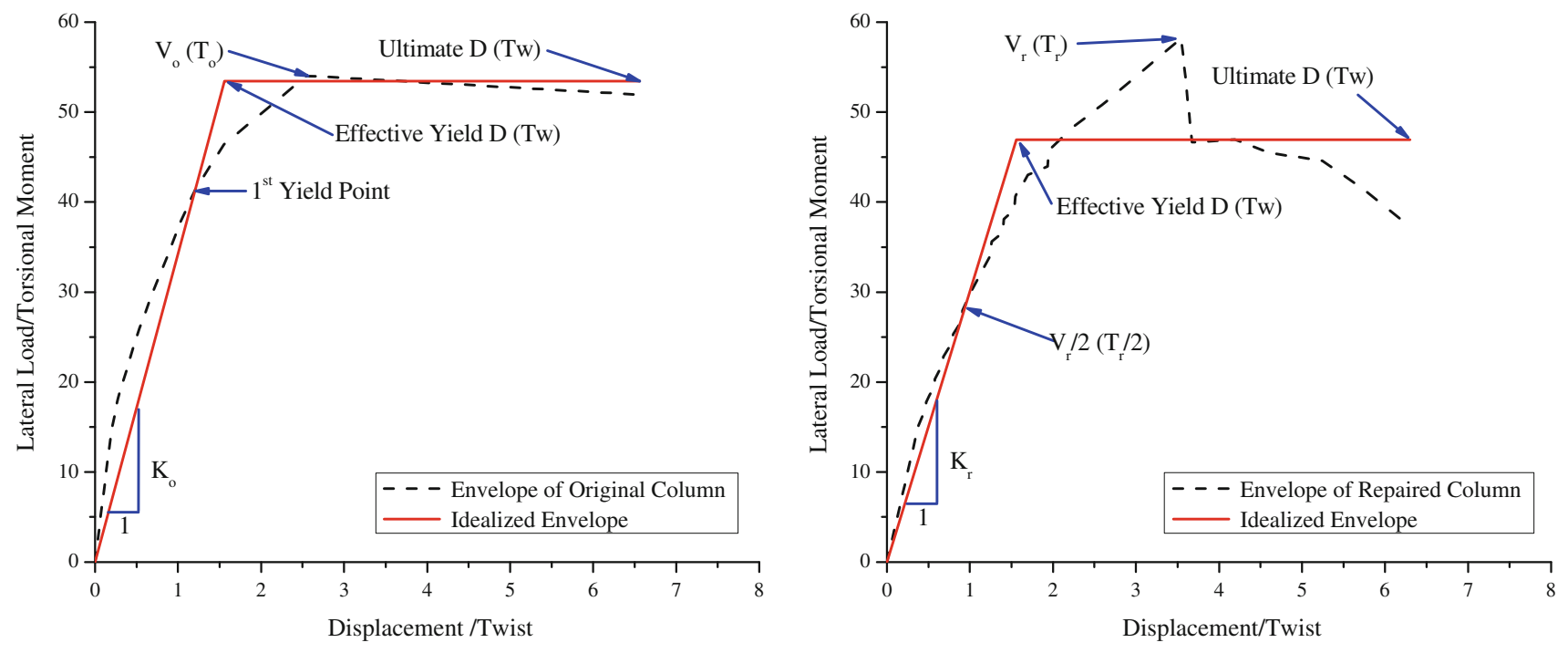

Fig. 18 Idealized envelopes for original and repaired columns.

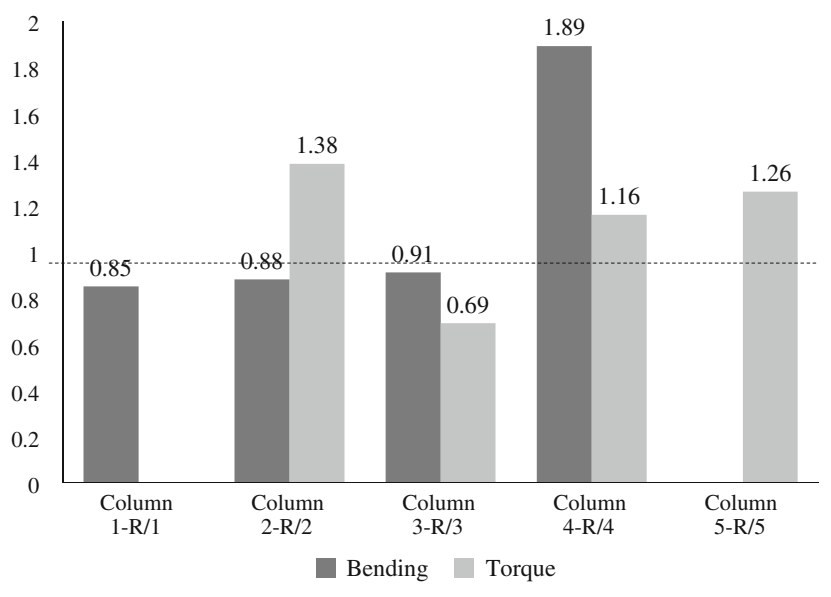

Fig. 19 General service stiffness indices for repaired columns.

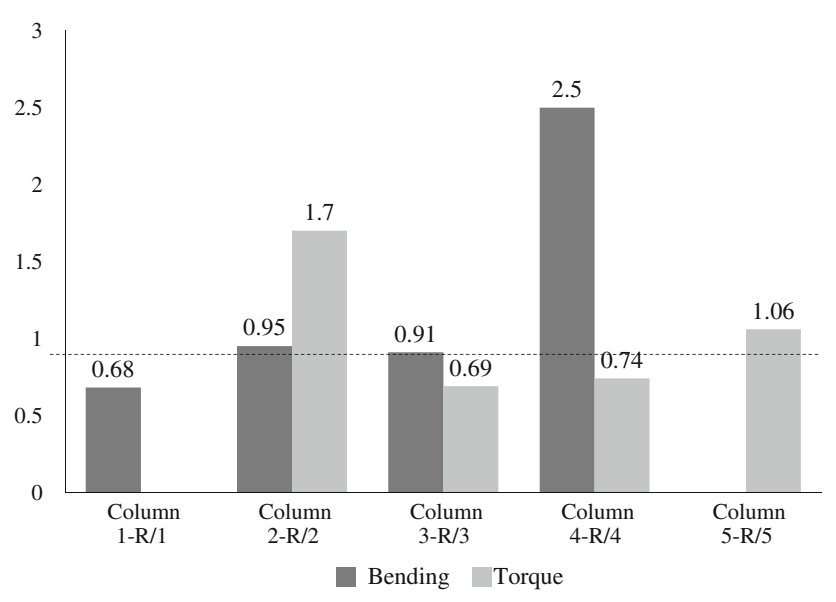

Fig. 20 Ductility indices for repaired columns.

\section{Conclusions}

This paper discusses the results of five large-scale tests conducted as a proof-of-concept in the effectiveness of a proposed method to rapidly repair severely damaged $\mathrm{RC}$ columns with different damage conditions. While the original geometric and material properties were nominally the same for each column, the location of plastic hinge and nature of damage were different because of different loading conditions. The repair procedure involved removal and replacement of loose concrete, followed by installation of longitudinal and transverse CFRP sheets. Because of the rapid nature of the repair, damaged reinforcing bars were left untreated. The repair of each column was designed to restore the strength associated with the peak load in the original test. While further study needs to be conducted to completely understand the design and performance of repaired RC columns subjected to combined loading effects including torsion, the following conclusions can be made from this study:

1. The developed repair procedure was practical and achievable as an emergency repair;

2. The repair method is effective in restoring the bending and/or torsional strength. Factors such as bendingtorque interaction, failure mode, and repair detailing played a role in the level of strength restored;

3. Results suggest that the repair method can restore the stiffness and ductility capacity of the columns to levels that can meet the needs of a temporary repair and allow emergency use after an earthquake;

4. In this study, for the flexural dominant columns with damage concentrated near the base, only the portion of the columns with severe damage, and the region immediately adjacent to it, were repaired. Results confirmed that the strength can be restored or even enhanced for columns without fractured longitudinal bars. These findings are significant in terms of time that can be saved in completing a temporary emergency repair;

5. The rapid repair method used in this study did not include repair of fractured longitudinal reinforcing bars. When fractured longitudinal bars (and critical section) are located near the base of the column, as was the case for Column 1 in this study, a large force demand is required of the CFRP strengthening system, as well as a substantial 
anchorage system to develop it. The method utilized in this study was found to be only partial unsuccessful in this case, since premature failure of the strengthening system limited the strength restoration; and

6. Though initial stiffnesses of the repaired columns were lower than that of original columns due to the unrepaired cracked portions, the general service stiffnesses were restored to a higher level. Also, the rate of stiffness deterioration under large reversal cyclic loading was lower for the repaired columns than that of the corresponding original columns.

\section{Acknowledgments}

The research was performed at Missouri S\&T. The authors would like to express their appreciation to the University of Missouri Research Board for the financial support for this project. BASF is gratefully acknowledged for providing the repair materials. Thanks are also due to research specialist, Jason Cox, research/lab technician, John Bullock, electronics technicians, Brian Swift and Gary Abbott, and the group members, Stephen Grelle, Corey Grace, Qian Li, and Yang Yang, for their help throughout the repair and testing processes.

\section{Open Access}

This article is distributed under the terms of the Creative Commons Attribution License which permits any use, distribution, and reproduction in any medium, provided the original author(s) and the source are credited.

\section{References}

ACI Committee 318. (2008). Building code requirements for structural concrete and commentary (ACI318-08). Farmington Hills, MI: American Concrete Institute.

ACI Committee 440. (2008). Guide for the design and construction of externally bonded FRP systems for strengthening concrete structures. ACI 440.2R-08. Farmington Hills, MI: American Concrete Institute.

Applied Technology Council (ATC). (1997). Seismic design criteria for bridges and other highway structures: Current and future. ATC-18, Redwood City.

ASTM. (2005). Standard test method for pull-off adhesion strength of coatings on concrete using portable pull-off adhesion testers. D7234-05. West Conshohocken, PA: ASTM International.

ASTM. (2012). Test methods and definitions for mechanical testing of steel products. A370-12a. West Conshohocken, PA: ASTM International.

California Department of Transportation. (2004). Caltrans bridge design specification. Sacramento, CA: California Department of Transportation.

California Department of Transportation. (2006). Seismic design criteria (SDC), version 1.4. Sacramento, CA: Engineering Service Center, Earthquake Engineering Branch.
California Department of Transportation. (2007). Memo to designers 20-4, attachment B. Sacramento, CA: Engineering Service Center, Earthquake Engineering Branch.

Chai, Y. H., Priestley, M. J. N., \& Seible, F. (1991). Seismic retrofit of circular bridge columns for enhanced flexural performance. ACI Structural Journal, 88(5), 572-584.

Cheng, C. T., Yang, J. C., Yeh, Y. K., \& Chen, S. E. (2003). Seismic performance of repaired hollow-bridge piers. Construction and Building Materials, 17(5), 339-351.

Elkin, S. J., Nacamuli, A. M., Lehman, D. E., \& Moehle, J. P. (1999). Seismic performance of damaged bridge columns. Earthquake Engineering and Engineering Seismology, 1(1), 39-50.

Grelle, S. V. (2011). Categorization and experimental evaluation of anchorage systems for FRP laminates bonded to reinforced concrete structures. Master's Thesis, Missouri University of Science and Technology, Rolla, MO.

Jing, M., Raongjant, W., \& Li, Z. (2007). Torsional strengthening of reinforced concrete box beams using carbon fiber reinforced polymer. Composite Structures, 78(2), 264-270.

Lehman, D. E., Gookin, S. E., Nacamuli, A. M., \& Moehle, J. P. (2001). Repair of earthquake-damaged bridge columns. ACI Structural Journal, 98(2), 233-242.

Park, R., \& Paulay, T. (1975). Reinforced concrete structures. New York: Wiley.

Prakash, S. S., Li, Q., \& Belarbi, A. (2012). Behavior of circular and square reinforced concrete bridge columns under combined loading including torsion. ACI Structrual Journal, 109(3), 317-327.

Rojahn, C., Mayer, R., Anderson, D. G., Clark, J., Hom, J. H., Hutt, R. V., \& O'Rourke, M. J. (1997). Seismic design criteria for bridges and other highway structures. Redwood City, CA: Applied Technology Council.

Saadatmanesh, H., Ehsani, M., \& Jin, L. (1997). Repair of earthquake-damaged RC columns with FRP wraps. ACI Structural Journal, 94(2), 206-215.

Stoppenhagen, D. R., Jirsa, J. Q., \& Wyllie, L. A. Jr. (1995). Seismic repair and strengthening of a severely damaged concrete frame. ACI Structural Journal, 92(2), 177-187.

Vosooghi, A., \& Saiidi, M. (2009). Rapid repair of high-shear earthquake-damaged RC bridge columns. In Proceedings of 25th US-Japan bridge engineering workshop, Tsukuba, Japan, Session 7.

Vosooghi, A., \& Saiidi, S. (2012). Design guidelines for rapid repair of earthquake-damaged circular RC bride columns using CFRP. Journal of Bridge Engineering. doi:10.1061/ (ASCE)BE.1943-5592.0000426.

Vosooghi, A., \& Saiidi, M. (2013). Shake-table studies of repaired reinforced concrete bridge columns using carbon fiber-reinforced polymer fabrics. ACI Structural Journal, 110(1), 105-114.

Vosooghi, A., Saiidi, M., \& Gutierrez, J. (2008). Rapid repair of RC bridge columns subjected to earthquakes. In Proceedings of 2nd international conference on concrete repair, rehabilitation, and retrofitting (ICCRRR 2008), Cape Town, South Africa, pp. 397-398. 